\title{
Antioxidant Activity in Bee Products: A Review
}

\author{
Marianna Martinello *(D) and Franco Mutinelli (D) \\ Istituto Zooprofilattico Sperimentale delle Venezie, NRL for Honey Bee Health, 35020 Legnaro, Italy; \\ fmutinelli@izsvenezie.it \\ * Correspondence: mmartinello@izsvenezie.it
}

Citation: Martinello, M.; Mutinelli, F. Antioxidant Activity in Bee Products: A Review. Antioxidants 2021, 10, 71. https://doi.org/10.3390/antiox 10010071

Received: 26 November 2020

Accepted: 4 January 2021

Published: 7 January 2021

Publisher's Note: MDPI stays neutral with regard to jurisdictional clai$\mathrm{ms}$ in published maps and institutional affiliations.

Copyright: $(\odot 2021$ by the authors. Licensee MDPI, Basel, Switzerland. This article is an open access article distributed under the terms and conditions of the Creative Commons Attribution (CC BY) license (https:// creativecommons.org/licenses/by/ $4.0 /)$.

\begin{abstract}
Bee products have been used since ancient times both for their nutritional value and for a broad spectrum of therapeutic purposes. They are deemed to be a potential source of natural antioxidants that can counteract the effects of oxidative stress underlying the pathogenesis of many diseases. In view of the growing interest in using bioactive substances from natural sources to promote health and reduce the risk of developing certain illnesses, this review aims to update the current state of knowledge on the antioxidant capacity of bee products such as honey, pollen, propolis, beeswax, royal jelly and bee venom, and on the analytical methods used. The complex, variable composition of these products and the multitude of analytical methods used to study their antioxidant activities are responsible for the wide range of results reported by a plethora of available studies. This suggests the need to establish standardized methods to more efficiently evaluate the intrinsic antioxidant characteristics of these products and make the data obtained more comparable.
\end{abstract}

Keywords: beeswax; honey; propolis; pollen; royal jelly; venom; antioxidant; polyphenols; honeybee; stingless bee

\section{Introduction}

Since ancient times, beekeeping products as honey, propolis, pollen, royal jelly, beeswax and bee venom have been among the most commonly used natural products in folk medicine by virtue of their powerful healing properties and high bioactive molecule content [1]. This branch of traditional medicine, with its scientific foundations, is now called apitherapy and is used to prevent or heal a number of different conditions, as wounds, rheumatic diseases, immune and neurologic conditions, and alimentary tract disorders, among others $[2,3]$. Nowadays, diet and a balanced life style are widely acknowledged to play an important role in the prevention and treatment of diseases. To improve their quality of life, modern consumers increasingly seek and use so-called natural functional foods containing bioactive substances of natural origin, thanks in part to their greater safety compared to synthetic drugs $[4,5]$. Scientific studies attribute to bee products a broad range of beneficial health effects, including antioxidant, antibacterial, anti-inflammatory, antitumor, antiviral properties, and many others [6,7]. One of the most important properties is their antioxidant capacity, which contributes to the prevention of certain illnesses, protecting cells against damage by oxidative agents such as free radicals. These are highly unstable, and therefore very reactive atoms, molecules or compounds due to their atomic or molecular structure, which has one or more unpaired electrons. They attempt to pair up with other molecules, atoms, or even individual electrons to create a stable compound, receiving electrons from other atoms. This generates reactive oxygen species (ROS), and free radicals bring about molecular transformations and gene mutations in many types of organisms. This is called oxidative stress and is deemed to contribute to the development of chronic and degenerative diseases such as cancer, autoimmune disorders, aging, cataracts, rheumatoid arthritis, and cardiovascular and neurodegenerative diseases [8]. ROS are produced naturally by metabolism or result from poor living conditions and environmental pollution [9]. The radical theory in human physiology claims that active free radicals are 
involved in almost all cellular degradation processes and lead to cell death. Antioxidants are molecules capable of slowing or inhibiting the oxidation of other molecules, thereby preventing such changes. Plant antioxidants display great bioactivity and molecular diversity and are present in honey and other bee products [10]. For example, since honey is produced by bees from nectar or plant secretions, various substances are transferred from plants and accumulated in this food. Consequently, the composition of honey, including its physical, chemical, organoleptic, and nutraceutical properties, is directly linked to the geographical, climatic and environmental characteristics of the areas where it is produced [11]. These differences represent a useful discriminatory tool for the classification and identification of honey.

The Apis mellifera L. honeybee currently dominates the world beekeeping market. However, this review considers another bee species, belonging to the family Hymenoptera and subfamily Meliponinae. They are known as "stingless bees" because their sting is greatly reduced and not used for defense purposes; rather, they defend their nest by biting $[12,13]$. They play a significant role in plant pollination, pollinating an estimated $40-90 \%$ of native or cultivated species in the tropics [13]. The Meliponini tribe consists of over 600 species (61 genera) distributed in tropical zones worldwide, mainly the Neotropics, South and Central America, tropical Africa, Southwest Asia, and Australia [13,14]. Stingless bees produce and store much less honey on a per hive basis (1-5 kg) than do A. mellifera bees, which are the world leader in honey production, with an average of $20 \mathrm{~kg}$ of honey per hive. For this reason, their honey is less well known, quality control standards are absent, and industrial production levels are low [12]. Stingless bee honey has gained attention in recent years owing to its distinctive characteristics, as its exotic flavor, and being more exposed to propolis, to its higher probability of becoming infused with plant-derived antimicrobial compounds compared to A. mellifera honey [15].

Our review on the antioxidant activity (AOA) of bee products focuses on the most recently published papers, from approximately 2010 to the present date, given the extent of the topic. We consider in more detail the "non-biological" AOA tests that use reagents to trigger a colorimetric reaction in the presence of antioxidant substances, allowing them to be determined qualitatively and quantitatively. We decided to focus on these chemical assays as they are more standardized, currently used for the determination of AOA and supported by the relevant literature. In vitro and in vivo studies are seldom used to quantify the AOA of bee products, with a wide variability in tests and results, which we will outline below. The antioxidant properties of bee products have been applied to biological systems in vitro and in vivo, e.g., on cell lines [16-29], blood cells [30-34], or in different types of diseases in animal models and humans $[3,35]$.

\section{Antioxidant Compounds in Bee Products}

Plant antioxidants are synthesized by plants to counteract biotic (pathogenic, predatory, competitive species) and abiotic (UV radiation, desiccation, thermal shock) stresses and favor the attraction of pollinators, the dispersion of seeds and allelopathic phenomena [9]. Secondarily, they affect the health of people who consume them through food, including honeybee products produced by bees from floral nectar, pollen, or plant secretions. Plant antioxidants are highly bioactive and present great molecular diversity, but phenolics (phenolic acids, flavonoids) are the most abundant and have the highest antiradical activity [36]. Phenolic compounds range from simple, low molecular-weight, single aromatic-ringed compounds to large, complex tannins and derived polyphenols [37]. Phenolic acids can be divided by chemical structure into hydroxybenzoic acids, with a C1-C6 nuclear structure derived from benzoic acid, with different methylation and hydroxylation of the aromatic ring (e.g., gallic acid, benzoic acid and vanillic acid); and hydroxycinnamic acids, with a C3-C6 general structure and differences in the originating ring substituents (e.g., caffeic acid, p-coumaric acid, ferulic acid, and cinnamic acid). Flavonoids have a C6-C3-C6 general structure, linking two benzene rings connected by a pyran ring, and can be classified into flavones, flavanones, and flavonols according to the type of substituent 
present on the ring (e.g., catechin, myricetin, quercetin, apigenin, kaempferol, luteolin, rutin, isorhamnetin, pinocembrin, or gallochatechin) [38]. The consulted literature refers only to active substances present in bee products and does not consider possible metabolites derived from honeybee metabolism. Furthermore, the assays used to determine the antioxidant compounds and AOA identify groups of compounds with similar chemical properties and not the single active substances. Different mechanisms underlie the antioxidant capacity of phenols, such as free-radical scavenging, donation of hydrogen, metal ion chelation, single oxygen quenching, and action as a substrate for superoxide and hydroxyl radicals $[39,40]$. These mechanisms are strictly linked to the metabolites and their molecular structure, e.g., the readiness of hydrogen donation may be affected by the steric hindrance of the carboxyl group, located next to the hydroxyl group. This indicates that the number and position of hydroxyl groups in phenolic compounds are paramount to the scavenging capacity of antioxidants [41]. AOA is highly correlated with phenolic compounds, but bee products are multicomponent natural substances and therefore also contain other substances presenting AOA, including minerals, amino acids, peptides, proteins, organic acids, and enzymes, but at lower concentrations than phenols [38]. Type and concentration are primarily influenced by the bee product in question, followed by botanical source, geographical and entomological origin, and climatic conditions [35].

\section{Determination of Antioxidant Compounds and Activity}

A broad array of assays is available to quantify phenolic content and AOA within plant extracts and pure compounds. There is no official method for AOA determination and none of the methods used are ideal, each being designed to measure a different group of antioxidants. Different methods can yield different results since oxidation is a complex process occurring in several stages in vivo and AOA can be measured by different mechanisms. For example, some methods are based on the electron or hydrogen transfer reaction, others are designed to evaluate the ability to inhibit the formation of ROS or the chelation of metal ions. Given the complexity of in vivo antioxidant action mechanisms, and the complex interactions between intrinsic and extrinsic factors present in biological matrices, several laboratory assays have been developed and are often performed on the same sample to more closely investigate the antioxidant potential of natural products. Antioxidants can respond differently to different radical or oxidant sources, and no single assay will accurately reflect all radical sources or all antioxidants in a mixed or complex system. Table 1 summarizes the methods of quantifying the bioactive molecules and AOA of the beehive products most commonly encountered in drawing up this review [42-68]. 
Table 1. Summary of the assays used for antioxidant capacity determination.

\begin{tabular}{|c|c|c|c|c|}
\hline Assay & Reaction Mechanisms & Methods in Brief & Main Characteristics & Set up Method Reference \\
\hline $\begin{array}{l}\text { Total phenolic (phenols and } \\
\text { polyphenols) content (TPC) }\end{array}$ & Electron transfer & $\begin{array}{l}\text { Reduction of a yellow molybdate-tungstate } \\
\text { reagent (Folin-Ciocalteu reagent) induced by the } \\
\text { phenols in the sample, under alkaline conditions, } \\
\text { a blue-colored chromophore (abs. 700, 740, 750, } \\
760 \text { or } 765 \mathrm{~nm} \text { ). }\end{array}$ & $\begin{array}{l}\text { Simple, rapid, and reproducible method. } \\
\text { Sensitive to nonphenolic electron donating } \\
\text { antioxidants as reducing sugars, amino acids, } \\
\text { ascorbic acid, Cu (I) }[42,43] .\end{array}$ & [44] \\
\hline Total flavonoids content (TFC) & Colored complex formation & $\begin{array}{l}\text { Aluminum chloride forms acid stable yellow } \\
\text { complexes with the C-4 keto groups and either } \\
\text { the C-3 or the C-5 hydroxyl group of flavones } \\
\text { and flavonols. In addition, it forms acid labile } \\
\text { complexes with the orthodihydroxyl groups in } \\
\text { some flavonoid rings (abs } 420 \text { or } 510 \mathrm{~nm} \text { ). }\end{array}$ & $\begin{array}{l}\text { Possible overestimation as some nonflavonoid } \\
\text { compounds exhibit absorbance at the same } \\
\text { wavelength. Specific only for flavones and } \\
\text { flavonols [45]. }\end{array}$ & [46] \\
\hline $\begin{array}{l}\text { DPPH (1,1-diphenyl-2-picrylhydrazyl) } \\
\text { free radical-scavenging assay }\end{array}$ & Electron transfer & $\begin{array}{l}\text { The decolorization of DPPH occurs from purple } \\
\text { to yellow when the unpaired electron of DPPH } \\
\text { forms a pair with a hydrogen donated by a free } \\
\text { radical scavenging antioxidant, thus converting } \\
\text { DPPH into its reduced form (abs. } 515 \text { or } 517 \mathrm{~nm} \text { ). }\end{array}$ & $\begin{array}{l}\text { Easy, simple, rapid, reproducible, and reasonably } \\
\text { costly method. Efficient for thermally unstable } \\
\text { compounds and highly sensitive [42,47]. } \\
\text { Unaffected by metal ion chelation and enzyme } \\
\text { inhibition [48]; reflects only the activity of } \\
\text { water-soluble antioxidants [ } 49] \text {. Sensitive to light, } \\
\text { oxygen, and impurities. Rate-limited by a proton } \\
\text { transfer step, affected by the solvent system and } \\
\text { the ionization equilibrium of phenol and } \\
\text { phenolate compounds in solution [50]. }\end{array}$ & [51] \\
\hline $\begin{array}{l}\text { Ferric reducing antioxidant power } \\
\text { (FRAP) assay }\end{array}$ & Electron transfer & $\begin{array}{l}\text { Reduction of a ferric 2,4,6-tripyridyl-s-triazine } \\
\text { complex (Fe } \mathrm{Fe}^{3+} \text {-TPTZ) to its ferrous, violet-blue } \\
\text { form ( } \mathrm{Fe}^{2+} \text {-TPTZ) in the presence of antioxidants } \\
\text { (abs. } 593 \text { or } 700 \mathrm{~nm})\end{array}$ & $\begin{array}{l}\text { Simple, reproducible, and sensitive. The high } \\
\text { amount of reducing sugars in honey could } \\
\text { contribute to higher reducing antioxidant power. } \\
\text { Unable to detect slowly-reacting polyphenolic } \\
\text { compounds and thiols [48]. }\end{array}$ & [52] \\
\hline $\begin{array}{l}\text { Cupric ion reducing antioxidant } \\
\text { capacity (CUPRAC) Assay }\end{array}$ & Electron transfer & $\begin{array}{l}\text { Bis(neocuproine)copper(II) chloride }[\mathrm{Cu}(\mathrm{III})-\mathrm{Nc}] \\
\text { reacts with polyphenols where the reactive } \\
\text { Ar-OH groups of polyphenols are oxidized to the } \\
\text { corresponding quinones and } \mathrm{Cu} \text { (II)-Nc is } \\
\text { reduced to the highly colored } \mathrm{Cu}(\mathrm{I})-\mathrm{Nc} \text { (abs } \\
450 \mathrm{~nm}) .\end{array}$ & $\begin{array}{l}\text { Carried out at pH } 7.0 \text { and simultaneously } \\
\text { measure hydrophilic and lipophilic antioxidants. } \\
\text { Fast enough to oxidize glutathione and thiol-type } \\
\text { antioxidants [53]. }\end{array}$ & [54] \\
\hline Reducing power method (RP) & $\begin{array}{l}\text { Electron transfer/ Hydrogen atom } \\
\text { transfer reaction. }\end{array}$ & $\begin{array}{l}\text { Substances, which have reduction potential, } \\
\text { react with potassium ferricyanide }\left(\mathrm{Fe}^{3+}\right) \text { to form } \\
\text { potassium ferrocyanide }\left(\mathrm{Fe}^{2+}\right) \text {, which then reacts } \\
\text { with ferric chloride to form ferric ferrous } \\
\text { complex (abs. } 700 \mathrm{~nm}) .\end{array}$ & $\begin{array}{l}\text { Chelating effect of the ions } \mathrm{Fe}^{3+} \text { of polyphenols } \\
\text { related to the highly nucleophilic aromatic rings. } \\
\text { The degree of hydroxylation and methylation of } \\
\text { the phenolic compound and the presence of other } \\
\text { non-phenolic compounds such as enzymes and } \\
\text { non-enzyme materials possibly involved [55]. }\end{array}$ & [56] \\
\hline
\end{tabular}


Table 1. Cont

Assay $\quad$ Reaction Mechanisms $\quad$ Methods in Brief

Total antioxidant capacity (TAA)/

phosphomolybdenum method

Electron transfer

Based on the reduction of $\mathrm{Mo}(\mathrm{VI})$ to $\mathrm{Mo}(\mathrm{V})$ by the reducing compounds and the formation of a green phosphate/Mo(V) complex at acidic $\mathrm{pH}$ (abs. $695 \mathrm{~nm})$.

Ferrozine can form a complex with a red color by forming chelates with $\mathrm{Fe}^{2+}$. This reaction is restricted in the presence of other chelating

Ferrous ion-chelating activity

Metal-chelating activity

agents and results in a decrease of the red color of the ferrozine- $\mathrm{Fe}^{2+}$ complexes. EDTA or citric acid can be used as a positive control (abs. $562 \mathrm{~nm}$ ).

Measuring the decrease in fluorescence of a

protein (fluorescein) that results from the loss of its conformation when it suffers oxidative

Oxygen radical absorbance capacity (ORAC) method

Hydrogen atom transfer reaction damage caused by a source of peroxyl radicals $\left(\mathrm{ROO}^{\bullet}\right)$ generated by the thermolytic breakdown of 2,2'-azobis(amidinopropane) dihydrochloride (AAPH) (excit. $485 \pm 20 \mathrm{~nm}$ emiss. $528 \pm 20 \mathrm{~nm}$ )

ABTS (2,2-azino-bis(3-

ethylbenzthiazoline-6-sulfonic acid) radical cation decolorization

assay/Trolox equivalent antioxidant capacity (TEAC) method

Electron transfer

When an antioxidant is added to the ABTS ${ }^{\bullet}$ blue-green chromophore, it is reduced to ABTS and discolored (abs. 734 or $750 \mathrm{~nm}$ ).

Superoxide radical (SOD) scavenging activity assay
Superoxide scavenging potential
Superoxide radicals are produced by

NADH/PMS (phenazine methosulfate) system ia the oxidation of $\mathrm{NADH}$, bringing about the reduction of nitroblue tetrazolium (NBT) to purple formazan (abs. $560 \mathrm{~nm}$ ).

\section{Main Characteristics}

Set up Method Reference

Simple, sensitive, and cheap method to evaluate water-soluble and fat-soluble antioxidants. Bad correlation with bioactive compounds (phenolics, flavonoids) and weak correlation with free radical scavenging assays (DPPH). Non-specific, detecting also ascorbic acid, carotenoids, and $\alpha$-tocopherol [42].

Bivalent transition metal ions can lead to the formation of hydroxyl radicals and

hydroperoxide decomposition reactions. Simple, reproducible, and cheap but non-specific reacting also with peptides and sulphates [42]

Both hydrophilic and hydrophobic antioxidants

solvent. Use reactants with a redox potential and mechanism of reaction similar to those of physiological oxidants at a physiological $\mathrm{pH}$. The most biologically relevant assays [60].

A "nonphysiological" radical source used over a

Dangerous hydroxyl radicals and singlet oxygen

They bear resemblance to biological systems in contrast to DPPH or ABTS, which are synthetic
Iron chelation can delay these processes [58]. detected by altering the radical source and wide $\mathrm{pH}$ range and in multiple media to determine both hydrophilic and lipophilic antioxidant capacities [60] are produced by superoxide anions,

both contributing to oxidative stress [63].

radicals. Non-specific and expensive [42]. 
Table 1. Cont.

\begin{tabular}{|c|c|c|c|c|}
\hline Assay & Reaction Mechanisms & Methods in Brief & Main Characteristics & Set up Method Reference \\
\hline $\begin{array}{l}\text { Hydroxyl radical scavenging activity } \\
\text { assay }\end{array}$ & $\begin{array}{l}\text { Hydroxyl radical scavenging } \\
\text { potential }\end{array}$ & $\begin{array}{l}\text { Based on the competitive ability of the sample } \\
\text { with deoxyribose for hydroxyl radicals generated } \\
\text { from } \mathrm{Fe}^{3+} \text {-EDTA-ascorbic acid and } \mathrm{H}_{2} \mathrm{O}_{2} \text { reaction } \\
\text { mixture, leading to a decreased yield of } \\
\text { malondialdehyde-like products, which in turn } \\
\text { reduce the formation of the TBA-chromophore } \\
\text { (abs. } 520 \text { or } 532 \mathrm{~nm} \text { ). }\end{array}$ & $\begin{array}{l}\text { Hydroxyl radical, one of the potent reactive } \\
\text { oxygen species, reacts with polyunsaturated fatty } \\
\text { acid moieties of cell membrane phospholipids, } \\
\text { damaging the cell [63]. }\end{array}$ & [65] \\
\hline $\begin{array}{l}\text { Hydrogen peroxide scavenging } \\
\text { activity assay }\end{array}$ & $\begin{array}{l}\text { Hydrogen peroxide scavenging } \\
\text { potential }\end{array}$ & $\begin{array}{l}\text { The absorbance of a solution of hydrogen } \\
\text { peroxide in phosphate buffer (PBS) is acquired } \\
\text { before and after the addition of the sample } \\
\text { (abs. } 230 \mathrm{~nm} \text { ). }\end{array}$ & $\begin{array}{c}\text { Hydrogen peroxide may enter into the human } \\
\text { body through inhalation and eye or skin contact. } \\
\text { Rapidly decomposed into oxygen and water; } \\
\text { may produce hydroxyl radicals that can cause } \\
\text { DNA damage [63]. }\end{array}$ & [66] \\
\hline $\begin{array}{l}\beta \text {-Carotene-linoleic acid bleaching } \\
\text { assay (BCB) }\end{array}$ & Hydrogen transfer reaction & $\begin{array}{l}\text { Linoleic acid is oxidized by ROS produced by } \\
\text { oxygenated water. The products will initiate the } \\
\beta \text {-carotene oxidation, and, as the molecule loses } \\
\text { its double bonds, the compound loses its } \\
\text { characteristic orange color (abs. } 434 \mathrm{~nm} \text { ). }\end{array}$ & $\begin{array}{l}\text { Hydrogen transfer reactions are solvent and } \\
\text { pH-independent and usually quite rapid } \\
\text { (seconds to minutes). Reducing agents, including } \\
\text { metals, complicate these assays leading to } \\
\text { erroneously high reactivity [67]. }\end{array}$ & {$[68]$} \\
\hline
\end{tabular}


Plant polyphenols can act as reducing agents, hydrogen atom donators, singlet oxygen scavengers, or transition-metal ion chelators [53]. In general, according to the reaction mechanisms, methods can be divided into single electron transfer (SET) and hydrogen atom transfer (HAT) methods. SET methods detect the ability of an antioxidant substance to transfer an electron to reduce a compound, including radicals, carbonyls, and metals. Relative reactivity in SET methods is based primarily on deprotonation and the ionization potential of the reactive functional group, hence SET reactions are $\mathrm{pH}$ dependent [67]. SET methods include total phenolic content (TPC) determination, the 2,2-diphenyl-1picrylhydrazyl (DPPH) free-radical scavenging assay, and the ferric reducing/antioxidant power (FRAP) assay, among others. HAT methods measure the potential of an antioxidant to quench free radicals by hydrogen donation. HAT reactions are solvent, $\mathrm{pH}$ independent, and usually fast [67]. The presence of reducing agents, including metals, is a complication in HAT assays and can lead to erroneously high apparent reactivity [69]. These methods include ORAC and $\beta$-carotene bleaching assays. Other methods reflect, for example, the scavenging potential of different radicals, such as superoxide, hydroxyl, or hydrogen peroxide radicals. The detection methods most commonly used to evaluate the antioxidant properties of bee products are listed in Table 1. We endeavored to trace the original methods most frequently cited by the studies considered in our review, which explains why some references date back much further than the last ten years on which we sought to focus.

Results are often expressed as equivalents, calculated through calibration curves using standard antioxidant substances, such as gallic acid (GAE) for the TPC assay; catechin (CAE), quercetin (QE), and rutin (RE) for TFC determination; Trolox (6-hydroxy-2,5,7,8tetramethylchroman-2-carboxylic acid, TE), a water-soluble analog of vitamin E, and ascorbic acid (AAE) for DPPH, ABTS, ORAC, and CUPRAC assays; and $\mathrm{FeSO}_{4}{ }^{*} 7 \mathrm{H}_{2} \mathrm{O}\left(\mathrm{Fe}^{2+}\right)$ for FRAP.

AOA can be expressed as a percentage of radical scavenging activity (\%RSA), calculated as follows:

$$
\% \operatorname{RSA}=[(\mathrm{B}-\mathrm{A} / \mathrm{B})] \times 100
$$

where B means "before" absorbance and refers to absorbance from the reagents without adding the sample (blank), and A means "after" absorbance, which refers to absorbance of the sample after the reaction.

Another way to express the result is by the extract concentration providing $50 \%$ of radical scavenging activity (e.g., the concentration of honey sample needed to scavenge $50 \%$ of DPPH), defined as EC50. The \% RSA is plotted against the sample concentration and the EC50 value is calculated from the graph by linear regression analysis. The lower the EC50 value, the higher the scavenging capacity of the sample, as a less radical scavenger is required to reduce, say, DPPH.

Even when investigators use the same method, modifications are often incorporated (e.g., the extraction solvent, volume or procedure, incubation time, reference standard, etc.), making it hard to compare the results of the same test performed by different laboratories.

\section{Honey}

Council Directive 2001/110/EC relating to honey [70] stipulates that honey is "the natural sweet substance produced by $A$. mellifera bees from the nectar of plants or secretions of living parts of plants or excretions of plant-sucking insects on the living parts of plants, which the bees collect, transform by combining with specific substances of their own, deposit, dehydrate, store and leave in honeycombs to ripen and mature" (Annex I, point 1). Honey has been used by humans as a medicinal remedy since ancient times [71], from ancient Egyptian and classical civilizations (Greeks and Romans), who used it in medicinal or cosmetic formulations or as an embalming substance, to Arab peoples in the Middle Ages, for whom honey was the basis of pharmacy, as reflected in the Koran. Later, with the advent of antibiotics and other drugs, the use of honey for curative purposes was abandoned, mainly due to the absence of evidence-based studies. In recent decades, however, several investigations have demonstrated and explained the bioactive properties 
for which honey was empirically used [43]. One therapeutic property is the presence, among its various components, of natural antioxidants.

Honey contains about 200 compounds, consisting mainly of sugars (fructose $25-45 \%$ and glucose $20-40 \%$ ), water, and other substances, such as amino acids, enzymes, protein, vitamins, minerals, ash, organic acids, and phenolic and flavonoid compounds, which greatly contribute to its biological activity [72]. The therapeutic potential of honey is associated with the presence, variety, and quantities of bioactive compounds. This in turn depends on the type of flora, geographical location of production, climatic conditions, seasonal factors, soil composition, as well as the production process [73,74]. Consideration should also be given to the influence that analytical methods, such as sample dilution and chromatographic conditions, can have on this type of analysis. The vast majority of bioactive compounds in honey consist of molecules with phenolic structures, such as phenolic acids, flavonoids, procyanidins, and anthocyanins, vitamin C (ascorbic acid), vitamin E, carotenoids, enzymes (e.g., catalase, peroxidase), Maillard reaction products, and trace elements $[48,75]$. The basic composition of phenolic compounds in different varieties of honey is relatively similar and includes phenolic acids, such as caffeic, ellagic, ferulic, and p-coumaric acids; flavonoids, including apigenin, chrysin, galangin, hesperetin, kaempferol, pinocembrin, and quercetin; and antioxidants, such as tocopherols, ascorbic acid, superoxide dismutase (SOD), catalase (CAT), and reduced glutathione (GSH) [76]. Nonetheless, honey can contain some variety-specific compounds which can be used as markers of botanical origin [77].

Table 2 summarizes the results of the most recent publications on honey AOA $[6,9,14,19,36,39,43,48,55,60,72,74,75,77-117]$. The first general observation is to confirm the well-known positive correlation between phenolic content, color, and AOA of honey. This has been clearly demonstrated by Al-Farsi et al. [78], Can et al. [36], and Kuś et al. [99], among others, who spectrophotometrically assessed the color intensity of honey. Honey color depends on nectar source, pollen content, phenolic compounds, ash, minerals, and Maillard reaction products. Generally, dark-colored honeys have been reported to possess high levels of these substances and, for example, buckwheat and heather honey are characteristically dark brown, almost black in color. These varieties of honey are often the richest sources of antioxidants, and can reduce ROS-induced oxidative stress $[19,90,99]$. There is usually a correlation between TPC, TFC, and AOA, but similar TPC and TFC content does not always correspond to similar antioxidant capacity $[43,78]$. This is because the overall antioxidant capacity of each sample results from the combined activity of other nonphenolic compounds, although phenols do remain the largest class of antioxidants found in nature [114]. 
Table 2. Summary of the results from studies on antioxidant capacity in honey.

\begin{tabular}{|c|c|c|c|c|c|c|c|c|}
\hline Sample Size & Botanical Origin & Bee Species $^{1}$ & Country & TPC $^{2}$ & $\mathrm{TFC}^{3}$ & $\mathrm{AOA}^{4}$ & Characterization & References \\
\hline 26 & $\begin{array}{c}10 \text { Sumer, } 10 \text { Sidr and } 6 \\
\text { multiflora }\end{array}$ & A. mellifera & Oman & $\begin{array}{l}842-2898 \mathrm{mg} \\
\mathrm{GAE} / \mathrm{kg}\end{array}$ & $521-2890 \mathrm{mg} \mathrm{CE} / \mathrm{kg}$ & 7.8-190.1 mg/mL EC50 DPPH & n.d. & [78] \\
\hline 11 & $\begin{array}{c}1 \text { Talh, } 1 \text { Olive, } 1 \text { Sidr, } 8 \\
\text { multiflora }\end{array}$ & n.s. & Saudi Arabia & $0.78-5.02 \mathrm{mg} \mathrm{GAE} / \mathrm{g}$ & n.d. & $5.89-53.93 \% \mathrm{DPPH}$ & GC-MS & [79] \\
\hline 83 & $\begin{array}{c}17 \text { Linen vine, } 16 \text { Morning } \\
\text { glory, } 18 \text { Christmas vine, } \\
16 \text { Black mangrove, } 16 \\
\text { Singing bean }\end{array}$ & n.s. & Cuba & $\begin{array}{l}213.9-595.8 \mathrm{mg} \\
\mathrm{GAE} / \mathrm{kg}\end{array}$ & $10-25 \mathrm{mg}$ CE $/ \mathrm{kg}$ & $\begin{array}{l}\text { 27.0-96.9 } \mu \mathrm{mol} \text { TE} / 100 \mathrm{~g} \text { FRAP } \\
\text { 103.5294.5 } \mu \mathrm{mol} \text { TE } / 100 \mathrm{~g} \text { TEAC }\end{array}$ & n.d. & {$[80]$} \\
\hline 32 & $\begin{array}{c}\text { Different monoflora and } 2 \\
\text { honeydew }\end{array}$ & $\begin{array}{l}\text { A. mellifera spp. } \\
\text { sicula }\end{array}$ & Italy & $\begin{array}{c}16.5-133.3 \mathrm{mg} \\
\text { GAE } / 100 \mathrm{~g}\end{array}$ & $\begin{array}{l}4.0-82.1 \mathrm{mg} \\
\mathrm{QE} / 100 \mathrm{~g}\end{array}$ & $\begin{array}{c}\text { 17.8-165.7 mg AAE/100g FRAP } \\
8.5-238.4 \mu \mathrm{mol} \mathrm{TE} / 100 \mathrm{~g} \text { DPPH } \\
19.2-270.34 \mu \mathrm{mol} \mathrm{TE} / 100 \mathrm{~g} \\
\text { ABTS }\end{array}$ & n.d. & [74] \\
\hline 32 & $\begin{array}{l}\text { Multiflora, } 8 \text { for each } \\
\text { bee species }\end{array}$ & $\begin{array}{l}\text { M. bicolor, } \\
\text { M. quadrifasciata, } \\
\text { M. marginata, } \\
\text { S. bipuncata }\end{array}$ & Brazil & $\begin{array}{l}220.4-708.1 \mathrm{mg} \\
\mathrm{GAE} / \mathrm{kg}\end{array}$ & n.d. & $\begin{array}{c}1.61-34.73 \mu \mathrm{mol} \mathrm{TE} / \mathrm{kg} \text { ABTS } \\
9.71-39.10 \mu \mathrm{mol} \mathrm{TE} / \mathrm{kg} \text { DPPH } \\
35.49-94.35 \mu \mathrm{mol} \mathrm{TE} / \mathrm{kg} \text { ORAC }\end{array}$ & HPLC-PDA & {$[60]$} \\
\hline 14 & n.s. & n.s. & Lithuania & $\begin{array}{l}168-278 \mathrm{mg} \\
\mathrm{GAE} / 100 \mathrm{~g}\end{array}$ & n.d. & $65-88 \% \mathrm{DPPH}$ & n.d. & [6] \\
\hline 8 & $\begin{array}{l}\text { Multiflora from } 6 \text { different } \\
\text { Meliponinae }\end{array}$ & Meliponinae, 6 spp. & Brazil & $\begin{array}{l}10.4-57.4 \mathrm{mg} \\
\text { GAE } / 100 \mathrm{~g}\end{array}$ & n.d. & $\begin{array}{c}0.8-28.2 \mathrm{mg} \text { AAE } / 100 \mathrm{~g} \text { DPPH } \\
67.5-734.5 \mu \mathrm{mol} \mathrm{Fe}{ }^{2+} / 100 \mathrm{~g} \\
\text { FRAP }\end{array}$ & LC-MS & [82] \\
\hline 33 & $\begin{array}{l}\text { Multiflora from } 10 \\
\text { different Meliponinae }\end{array}$ & Meliponinae, 10 spp. & Brazil & $\begin{array}{c}10.3-98.0 \mathrm{mg} \\
\mathrm{GAE} / 100 \mathrm{~g}\end{array}$ & n.d. & $\begin{array}{l}\text { 1.41-18.5 mg AAE/100g DPPH } \\
61.1-624 \mu \mathrm{mol} \mathrm{Fe}{ }^{2+} / 100 \mathrm{~g} \text { FRAP }\end{array}$ & n.d. & [83] \\
\hline 13 & $\begin{array}{l}\text { Multiflora from } 9 \text { different } \\
\text { Meliponinae }\end{array}$ & Meliponinae, 9 spp. & Brazil & & n.d. & 199-667 $\mu \mathrm{mol} \mathrm{TE} / 100 \mathrm{~g}$ ORAC & $\begin{array}{l}\text { HPLC-ESI- } \\
\text { MS/MS }\end{array}$ & [14] \\
\hline 14 & 8 Rape and 8 multiflora & n.s. & Hungary & 170-330 mg GAE $/ \mathrm{kg}$ & n.d. & $\begin{array}{c}\text { 63-110 } \mu \mathrm{mol} \mathrm{TE} / 100 \mathrm{~g} \text { TEAC } \\
27-42 \mathrm{mg} \text { TE/mL EC50 DPPH } \\
22-39 \mu \mathrm{molTE} / \mathrm{g} \text { ORAC }\end{array}$ & n.d. & [84] \\
\hline 20 & Avocado & n.s. & Spain & $\begin{array}{l}103.1-137.8 \mathrm{mg} \\
\text { GAE/100g }\end{array}$ & n.d. & 2.4-2.8 $\mu \mathrm{mol} \mathrm{TE} / \mathrm{g}$ TEAC & n.d. & [85] \\
\hline
\end{tabular}


Table 2. Cont.

\begin{tabular}{|c|c|c|c|c|c|c|c|c|}
\hline Sample Size & Botanical Origin & Bee Species ${ }^{1}$ & Country & TPC $^{2}$ & $\mathrm{TFC}^{3}$ & $\mathrm{AOA}^{4}$ & Characterization & References \\
\hline 62 & $\begin{array}{l}11 \text { monoflora, } 2 \text { honeydew } \\
\text { and } 7 \text { multiflora }\end{array}$ & n.s. & Turkey & $\begin{array}{l}16.02-120.04 \mathrm{mg} \\
\text { GAE/100g }\end{array}$ & $\begin{array}{l}0.65-8.10 \mathrm{mg} \\
\mathrm{QE} / 100 \mathrm{~g}\end{array}$ & $\begin{array}{c}0.64-4.30 \mu \mathrm{mol} \mathrm{Fe}^{2+} / \mathrm{g} \text { FRAP } \\
12.56-152.40 \mathrm{mg} \mathrm{TE} / \mathrm{mL} \text { EC50 } \\
\text { DPPH }\end{array}$ & HPLC-UV & [36] \\
\hline 15 & 8 monoflora, 7 multiflora & n.s. & Spain & $\begin{array}{l}23.1-158 \mathrm{mg} \\
\mathrm{GAE} / 100 \mathrm{~g}\end{array}$ & $\begin{array}{l}1.65-5.93 \mathrm{mg} \\
\text { CE } / 100 \mathrm{~g}\end{array}$ & $\begin{array}{c}5.46-202 \mathrm{mg} / \mathrm{mL} \text { EC50 DPPH } \\
26.3-215 \mathrm{mg} / \mathrm{mL} \text { EC50 RP } \\
-1.34-92.9 \% \text { BCB }\end{array}$ & HPLC-UV & [43] \\
\hline 7 & Multiflora & $\begin{array}{l}\text { M.(Michmelia) } \\
\text { seminigra merrilae }\end{array}$ & Brazil & $17.0-66.0 \mathrm{mg}$ GAE/g & n.d. & 210-337 mg TE/mL EC50 ABTS & HPLC-DAD & [87] \\
\hline 4 & Manuka & n.s. & New Zealand & 372-576 mg GAE/kg & n.d. & $545-756 \mu \mathrm{mol} \mathrm{Fe} e^{2+} / 100 \mathrm{~g}$ FRAP & n.d. & [88] \\
\hline 460 & Monoflora & n.s. & Italy & $\begin{array}{l}107.2-564.2 \mathrm{mg} \\
\mathrm{GAE} / \mathrm{kg}\end{array}$ & 33.1-213 mg QE/kg & $\begin{array}{c}3.4-161.3 \mathrm{mg} / \mathrm{mL} \text { EC50 DPPH } \\
24.4-72.8 \mu \mathrm{M} \text { AAE/g FRAP }\end{array}$ & LC-MS & [9] \\
\hline 31 & Multiflora & Meliponinae, 7 spp. & Brazil & 32-136 mg GAE/g & 8-55 mg QE/g & $\begin{array}{c}\text { DPPH, BCB, } \\
\text { FRAP (graphicated) }\end{array}$ & n.d. & [89] \\
\hline 20 & Buckwheat & n.s. & Poland & $\begin{array}{l}181-355 \mathrm{mg} \\
\mathrm{GAE} / 100 \mathrm{~g}\end{array}$ & $\begin{array}{l}8.0-30.4 \mathrm{mg} \\
\mathrm{QE} / 100 \mathrm{~g}\end{array}$ & $\begin{array}{c}51-95.2 \% \text { DPPH } \\
195-680 \mu \mathrm{mol} \mathrm{TE} / 100 \mathrm{~g} \text { FRAP }\end{array}$ & $\begin{array}{l}\text { UPLC-PDA- } \\
\text { MS/MS }\end{array}$ & [90] \\
\hline 90 & $\begin{array}{l}44 \text { monoflora, } 29 \\
\text { honeydew and } 17 \\
\text { multiflora }\end{array}$ & n.s. & Poland & $\begin{array}{l}254.5-1353.7 \mathrm{mg} \\
\text { GAE } / \mathrm{kg}\end{array}$ & n.d. & $\begin{array}{c}21.81-82.41 \% \mathrm{DPPH} \\
656.73-3635.49 \mu \mathrm{mol} \mathrm{TE} / \mathrm{kg} \\
\text { FRAP }\end{array}$ & n.d. & [48] \\
\hline 8 & Carob & n.s. & Morocco & $\begin{array}{l}\text { 75.5-245.2 mg } \\
\text { GAE/100g }\end{array}$ & $\begin{array}{l}2.26-4.79 \mathrm{mg} \\
\mathrm{QE} / 100 \mathrm{~g}\end{array}$ & $\begin{array}{c}\text { 35.03-60.94 mg AAE/g TAA } \\
12.54-23.52 \mathrm{mg} / \mathrm{mL} \text { EC50 DPPH } \\
1.9-4.4 \mathrm{mg} \text { AAE/mL EC50 } \\
\text { FRAP }\end{array}$ & n.d. & [91] \\
\hline 187 & $\begin{array}{c}34 \text { chestnut, } 17 \text { eucalyptus, } \\
31 \text { blackberry, } 10 \text { heather, } \\
13 \text { honeydew and } 82 \\
\text { multiflora }\end{array}$ & n.s. & Spain & $\begin{array}{l}78.4-181 \mathrm{mg} \\
\text { GAE /100g }\end{array}$ & $4.3-9.6 \mathrm{mg} \mathrm{QE} / 100 \mathrm{~g}$ & $\begin{array}{l}\text { 9.5-17.8 mg AAE/mL EC50 } \\
\text { DPPH }\end{array}$ & n.d. & [92] \\
\hline 32 & Honeydew & n.s. & Spain & $\begin{array}{l}79.5-187 \mathrm{mg} \\
\text { GAE / 100g }\end{array}$ & $\begin{array}{l}6.6-13.1 \mathrm{mg} \\
\mathrm{QE} / 100 \mathrm{~g}\end{array}$ & 52.9-95.6\% DDPH & n.d. & [93] \\
\hline 7 & $\begin{array}{l}\text { Forest, pine, urtica, } \\
\text { meadow, linden, } 2 \text { acacia }\end{array}$ & n.s. & $\begin{array}{l}\text { Serbia, Germany, } \\
\text { Greece }\end{array}$ & $\begin{array}{l}94.0-620.7 \mu \mathrm{g} \\
\mathrm{GAE} / \mathrm{ml}\end{array}$ & n.d. & $\begin{array}{c}0.2-4.98 \mu \mathrm{mol} \mathrm{TE} / \mathrm{g} \text { FRAP } \\
5.9-12.9 \mu \mathrm{mol} \text { TE/g ORAC } \\
1.0-5.82 \mu \mathrm{mol} \text { TE/g ABTS } \\
0-1.21 \mu \mathrm{mol} \mathrm{TE} / \mathrm{g} \text { EC50 DPPH }\end{array}$ & n.d. & [94] \\
\hline
\end{tabular}


Table 2. Cont.

\begin{tabular}{|c|c|c|c|c|c|c|c|c|}
\hline Sample Size & Botanical Origin & Bee Species ${ }^{1}$ & Country & TPC $^{2}$ & $\mathrm{TFC}^{3}$ & $\mathrm{AOA}^{4}$ & Characterization & References \\
\hline 23 & Monoflora & n.s. & Turkey & $\begin{array}{l}45.4-470.7 \mathrm{mg} \\
\text { GAE } / 100 \mathrm{~g}\end{array}$ & n.d. & $\begin{array}{c}12.01-65.52 \mathrm{mg} / \mathrm{mL} \text { EC50 DPPH } \\
0.0022-0.0091 \mathrm{mg} \text { TE } / 100 \mathrm{~g} \\
\text { FRAP } \\
\text { 32.09-94.87\% BCB. }\end{array}$ & n.d. & [95] \\
\hline 22 & $\begin{array}{l}20 \text { monoflora, } 2 \\
\text { honeydew }\end{array}$ & n.s. & Poland & $\begin{array}{l}3.43-22.33 \mathrm{mg} \\
\text { GAE } / 100 \mathrm{~g}\end{array}$ & n.d. & 41.42-83.16 mg GAE/100g ABTS & HPLC-DAD & [77] \\
\hline 40 & Honeydew "dryomelo" & A. mellifera & Greece & $\begin{array}{l}1221-1495 \mathrm{mg} \\
\mathrm{GAE} / \mathrm{kg}\end{array}$ & n.d. & $56.8-72.4 \% \mathrm{DPPH}$ & n.d. & [96] \\
\hline 4 & $\begin{array}{l}\text { Tualang, gelam, indian } \\
\text { forest, pineapple }\end{array}$ & n.s. & Malaysia & $\begin{array}{l}27.75-83.96 \mathrm{mg} \\
\mathrm{GAE} / 100 \mathrm{~g}\end{array}$ & $\begin{array}{l}24.74-50.45 \mathrm{mg} \\
\mathrm{QE} / 100 \mathrm{~g}\end{array}$ & $\begin{array}{c}16.12-53.06 \mathrm{mg} \text { AAE/g TAA } \\
5.80-10.86 \mathrm{mg} / \mathrm{mL} \mathrm{EC50} \mathrm{DPPH} \\
47.92-121.89 \mu \mathrm{mol} \mathrm{Fe}{ }^{2+} / 100 \mathrm{~g} \\
\text { FRAP }\end{array}$ & n.d. & [98] \\
\hline 28 & $\begin{array}{c}4 \text { black locust, } 5 \\
\text { buckwheat, } 4 \text { lime, } 2 \\
\text { goldenrod, } 3 \text { heather, } 10 \\
\text { rapeseed }\end{array}$ & n.s. & Poland & $\begin{array}{l}121.6-1173.8 \mathrm{mg} \\
\mathrm{GAE} / \mathrm{kg}\end{array}$ & n.d. & $\begin{array}{l}\text { 0.6-6.7 FRAP } \mathrm{mmol} \mathrm{Fe} \mathrm{e}^{2+} / \mathrm{kg} \\
0.2-1.4 \mathrm{mmol} \mathrm{TE} / \mathrm{kg} \mathrm{DPPH}\end{array}$ & HPLC-DAD & [99] \\
\hline 40 & $\begin{array}{l}\text { Multiflora, lime, rape, } \\
\text { raspberry, mixture, } \\
\text { honeydew }\end{array}$ & n.s. & Czech & $\begin{array}{l}82.5-242.5 \mathrm{mg} \\
\mathrm{GAE} / \mathrm{kg}\end{array}$ & n.d. & $\begin{array}{c}\text { 141.52-407.08 mg AAE } / \mathrm{kg} \\
\text { DPPH } \\
\text { 489.44-982.93 mg AAE } / \mathrm{kg} \\
\text { ABTS } \\
\text { 295.35-776.05 mg AAE } / \mathrm{kg} \\
\text { FRAP }\end{array}$ & n.d. & [100] \\
\hline 9 & 5 orange and 4 multifloral & n.s. & Brazil & $\begin{array}{c}40.36 \text { and } 58.05 \mathrm{mg} \\
\mathrm{GAE} / 100 \mathrm{~g}\end{array}$ & $\begin{array}{c}0.17 \text { and } 1.53 \mathrm{mg} \\
\mathrm{QE} / 100 \mathrm{~g}\end{array}$ & $\begin{array}{c}38.54 \text { and } 16.62-\mathrm{mg} / \mathrm{mL} \mathrm{EC50} \\
\text { DPPH }\end{array}$ & HPLC-DAD & [101] \\
\hline 6 & $\begin{array}{l}\text { B. pilosa, D. longan, L. } \\
\text { chinensis, C. maxima, A. } \\
\text { formosana, and } 1 \\
\text { multiflora }\end{array}$ & n.s. & China & $0.31-0.82 \mathrm{mg}$ GAE /g & 29.7-124 mg QE & $15.2-84.9 \% \mathrm{DPPH}$ & n.d. & [102] \\
\hline 20 & $\begin{array}{c}\text { Monoflora, multiflora and } \\
\text { Manuka }\end{array}$ & n.s. & $\begin{array}{c}\text { Florida, } \\
\text { New Zealand }\end{array}$ & 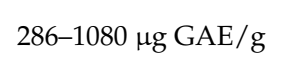 & n.d. & $\begin{array}{c}0.28-2.1 \mu \mathrm{mol} \text { TE/g DPPH } \\
1.48-18.2 \mu \mathrm{mol} \mathrm{TE} / \mathrm{g} \text { ORAC }\end{array}$ & HPLC-UV & [103] \\
\hline
\end{tabular}


Table 2. Cont.

\begin{tabular}{|c|c|c|c|c|c|c|c|c|}
\hline Sample Size & Botanical Origin & Bee Species $^{1}$ & Country & $\mathrm{TPC}^{2}$ & $\mathrm{TFC}^{3}$ & $\mathrm{AOA}^{4}$ & Characterization & References \\
\hline 4 & n.s. & n.s. & Algeria & $\begin{array}{l}15.84-61.63 \mathrm{mg} \\
\text { GAE/100g }\end{array}$ & $\begin{array}{l}2.07-10.15 \mathrm{mg} \\
\mathrm{CE} / 100 \mathrm{~g}\end{array}$ & RP (graphicated) & n.d. & [55] \\
\hline 20 & $\begin{array}{c}4 \text { multiflora, } 4 \text { linden, } 4 \\
\text { rapeseed, } 2 \text { sunflower, } 1 \\
\text { phacelia, } 3 \text { acacia and } \\
2 \text { honeydew }\end{array}$ & n.s. & Serbia & n.d. & n.d. & 22.96-79.45\% DPPH & n.d. & [72] \\
\hline 49 & $\begin{array}{l}28 \text { eucalyptus, } 6 \text { Japanese } \\
\text { grape, } 5 \text { mastic, } 3 \text { quitoco, } \\
1 \text { wildflower, } 6 \text { multiflora }\end{array}$ & A. mellifera & Brazil & $\begin{array}{l}26.0-100.0 \mathrm{mg} \\
\text { GAE } / 100 \mathrm{~g}\end{array}$ & $\begin{array}{l}0.65-8.10 \mathrm{mg} \\
\mathrm{QE} / 100 \mathrm{~g}\end{array}$ & $\begin{array}{c}1.28-18.48 \mu \mathrm{mol} \mathrm{TE} / \mathrm{g} \text { ORAC } \\
25.45-294.26 \mathrm{mg} / \mathrm{mL} \text { EC50 } \\
\text { DPPH } \\
0.22-2.11 \mu \mathrm{mol} \mathrm{TE} / \mathrm{g} \text { FRAP }\end{array}$ & HPLC-UV & [104] \\
\hline 37 & $\begin{array}{c}11 \text { apple, } 8 \text { cherry, } 8 \\
\text { saffron and } 10 \text { wild bush }\end{array}$ & n.s. & India & $\begin{array}{l}37-117 \mathrm{mg} \\
\mathrm{GAE} / 100 \mathrm{~g}\end{array}$ & 8-17 mg QE/100g & $\begin{array}{c}55-84 \% \text { DPPH } \\
19-51 \mathrm{mg} \mathrm{AAE} / 100 \mathrm{~g} \text { DPPH }\end{array}$ & HPLC-DAD & [105] \\
\hline 24 & $\begin{array}{l}7 \text { acacia, } 8 \text { pine, } 9 \\
\text { multiflora }\end{array}$ & n.s. & India & $\begin{array}{l}22.68-59.84 \mathrm{mg} \\
\text { GAE/100g }\end{array}$ & $\begin{array}{l}\text { 6.10-8.12 mg } \\
\text { QE } / 100 \mathrm{~g}\end{array}$ & $\begin{array}{c}52.27-55.37 \% \text { DPPH } \\
\text { 14.13-23.74 mg AAE/100g } \\
\text { DPPH }\end{array}$ & n.d. & [106] \\
\hline 16 & Monoflora & n.s. & Turkey & $\begin{array}{c}170.06-885.43 \mathrm{mg} \\
\mathrm{GAE} / 100 \mathrm{~g}\end{array}$ & n.d. & $\begin{array}{c}0.27-2.56 \mathrm{mg} / \mathrm{mL} \text { EC50 DPPH } \\
0.51-0.62 \mathrm{mmol} \mathrm{TE} / \mathrm{g}\end{array}$ & n.d. & [107] \\
\hline 45 & $\begin{array}{l}4 \text { thyme, } 10 \text { rape, } 10 \text { mint, } \\
6 \text { raspberry, } 9 \text { sunflower, } 6 \\
\text { multiflora }\end{array}$ & n.s. & Romania & $\begin{array}{l}18.91-23.71 \mathrm{mg} \\
\text { GAE/100g }\end{array}$ & $\begin{array}{l}17.45-33.58 \mathrm{mg} \\
\mathrm{QE} / 100 \mathrm{~g}\end{array}$ & $55.49-79.05 \%$ DPPH & HPLC-DAD & [75] \\
\hline 78 & $\begin{array}{c}16 \text { chestnut, } 14 \text { eucalyptus, } \\
12 \text { citrus, } 18 \text { sulla and } 18 \\
\text { multiflora }\end{array}$ & n.s. & Italy & $\begin{array}{l}10.82-14.67 \mathrm{mg} \\
\mathrm{GAE} / 100 \mathrm{~g}\end{array}$ & $\begin{array}{l}5.09-14.05 \mathrm{mg} \\
\mathrm{QE} / 100 \mathrm{~g}\end{array}$ & $\begin{array}{c}58.40-60.42 \% \text { ABTS } \\
\text { 152.65-881.34 } \mu \mathrm{M} \mathrm{Fe}^{2} \text { FRAP } \\
54.29-78.73 \% \text { DPPH }\end{array}$ & n.d. & [39] \\
\hline 14 & $\begin{array}{l}\text { Monoflora and } 5 \\
\text { multiflora }\end{array}$ & n.s. & Mexico & $\begin{array}{l}283.9-1142.9 \mathrm{mg} \\
\text { GAE } / \mathrm{kg}\end{array}$ & n.d. & $\begin{array}{c}\text { 910.2-2927.4 } \mu \mathrm{mol} \mathrm{TE} / \mathrm{kg} \text { ABTS } \\
81.9-255 \mu \mathrm{mol} \mathrm{TE} / \mathrm{kg} \mathrm{DPPH} \\
749.4-3097.1 \mu \mathrm{mol} \mathrm{Fe}{ }^{2+} / \mathrm{kg} \\
\text { FRAP } \\
\end{array}$ & n.d. & [108] \\
\hline 91 & $\begin{array}{l}53 \text { chestnut and } 38 \\
\text { honeydew }\end{array}$ & n.s. & Spain & $\begin{array}{l}125 \text { and } 128 \mathrm{mg} \\
\mathrm{GAE} / 100 \mathrm{~g}\end{array}$ & $\begin{array}{l}\text { 8.4and } 9.4 \mathrm{mg} \\
\mathrm{QE} / 100 \mathrm{~g}\end{array}$ & $58.4-68.4 \%$ DPPH & n.d. & [109] \\
\hline 129 & $\begin{array}{l}\text { Loco, opoponax-tree, } \\
\text { alfalfa, barberry, thyme, } \\
\text { argentine thistle and dill }\end{array}$ & n.s. & Iran & $\begin{array}{l}\text { 33.34-259.52 mg } \\
\text { GAE/kg }\end{array}$ & n.d. & $\begin{array}{c}\text { 204.14-1383.18 } \mu \mathrm{mol} \mathrm{Fe} \mathrm{F}^{2+} / 100 \mathrm{~g} \\
\text { FRAP }\end{array}$ & n.d. & [110] \\
\hline 39 & $\begin{array}{c}\text { Acacia, jujube, vitex, } \\
\text { linden, fennel, buckwheat, } \\
\text { Manuka }\end{array}$ & n.s. & China (mainly) & $\begin{array}{l}9.15-294 \mathrm{mg} \\
\text { GAE / } 100 \mathrm{~g}\end{array}$ & $\begin{array}{l}6.85-64.8 \mathrm{mg} \\
\mathrm{QE} / 100 \mathrm{~g}\end{array}$ & n.d. & UPLC-MS/MS & [19] \\
\hline
\end{tabular}


Table 2. Cont.

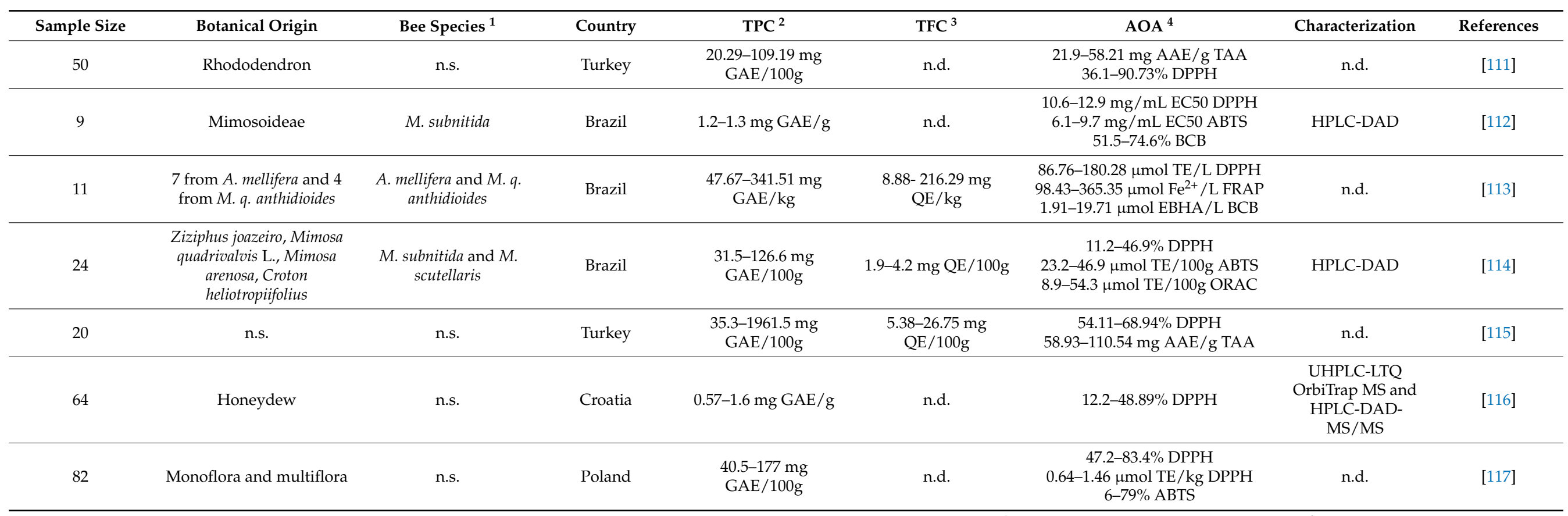

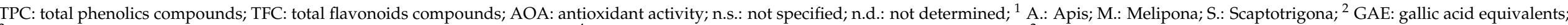

${ }^{3} \mathrm{CE}$ : catechin equivalents, QE: quercetin equivalents, RE: rutin equivalents; ${ }^{4} \mathrm{TE}$ : Trolox equivalents, AAE: ascorbic acid equivalents, $\mathrm{Fe}^{2+}$ : $\mathrm{FeSO}_{4}{ }^{*} 7 \mathrm{H}_{2} 0$ equivalents. $^{2}$ 
Honey composition and bioactivity were found to depend mainly on floral source, but external factors, such as geographical, seasonal, and environmental conditions, also play a role [84]. Comparing honey of the same botanical source but different geographical origin, Karabagias et al. [96] and Silici et al. [111] (located in Greece and Turkey, respectively) found TPC and AOA to be significantly affected by region. By contrast, Bodó et al. [84] reported that none of the antioxidant parameters were influenced by the Hungarian region of origin of their samples. As regards seasonality, Bartkiene et al. [6], for example, compared honey collected in spring and summer, observing that, on average, spring honeys had 25\% less TPC.

Another aspect studied in various works is the influence of the extraction solvent on the antioxidant power of honey. Lianda et al. [101] and Rodríguez et al. [108] evaluated TPC and AOA in both crude honey and its methanol extract, generally obtaining lower TPC content in extracts, but finding a different pattern for AOA. It is well known that minerals, especially iron, can complex with phenolic compounds, enhancing their AOA. The water cleansing process applied during extraction can remove most of the minerals in honey, as their complexes are mainly water soluble. In addition, glycosylated phenolic compounds may not be extracted in the methanolic phase or may be lost in the aqueous phase [108]. Accordingly, there could be considerable changes in AOA and phenolic compounds when comparing honey and its extract. In general, according to the studies evaluated, honey dissolved in water yields higher polyphenol values, while extraction with methanol results in higher flavonoid levels [55,101].

There is a growing body of scientific research supporting the therapeutic potential of Manuka honey. It is a dark, monofloral honey produced by honeybees foraging on the Manuka tree (Leptospermum scoparium) native to New Zealand and Australia, and is classified and sold according to its methylglyoxal concentration or "Unique Manuka Factor" (UMF) [103]. Manuka honey is known for its excellent AOA and antibacterial activity [17] and has consequently been used for comparison with honeys of different botanical origin in several works. Attanzio et al. [74] found significantly lower TPC, TFC, and AOA in Manuka honey than in ferula (Ferula communis), dill (Anethum graveolens), and honeydew honeys from Sicily, a region of southern Italy, but comparable levels to those found in honey from eucalyptus, a species belonging to the same Myrtaceae family as Manuka. Deng et al. [17] demonstrated that Chinese buckwheat honey possesses higher phenolic content and better antioxidant capacity than Manuka honey. Marshall et al. [103] compared Manuka honey with other monofloral and multifloral honeys from Florida, finding that Manuka honeys had the highest average TPC and AOA values of all honeys, which were proportional to the darkness of the honeys. Finally, Bolanos de la Torre et al. [88] found that the TPC and antioxidant capacity of Manuka honey was directly related to the UMF rating.

Another key factor affecting honey composition is its entomological origin. Honeys produced by distinct bee species or collected from different locations possess different active compounds, and consequently exhibit differences in biological properties [81]. Several studies have compared the antioxidant properties of honey produced by stingless bees with honey produced by $A$. mellifera [81,97], or by different species of stingless bees $[14,60,82,83,89,113,114]$. Melipona beecheii honey showed the highest values for total antioxidant capacity and total phenolic, flavonoid, carotenoid, ascorbic acid, free amino acid, and protein content compared to A. mellifera honey [81], while Trigona spp. honey yielded higher total phenolic content than Apis spp. [97], confirming that stingless bee honey possesses higher levels of antioxidant and biological activity than $A$. mellifera honey, as reported by Avila et al. [12]

\section{Pollen and Bee Bread}

Bee pollen results from agglutination, by nectar and honeybee enzymes (e.g., amylase, catalase), of pollen grains collected from flowers by bees. Bees add small amounts of salivary secretions, nectar and/or honey to the pollen grains. Bee pollen is referred to as the "only perfectly complete food" as it contains all the essential amino acids needed by the 
human organism [118]. Bee pollen contains proteins (5-60\%), reducing and non-reducing sugars (13-55\%), lipids (4-7\%), crude fibers $(0.3-20 \%)$, essential amino acids, minerals, and bioactive substances including vitamins, enzymes, and phenolic compounds, mainly flavonoids (3-8\% dry weight). Bee pollen AOA seems to be mainly related to phenolic acids, such as gallic, vanillic, protocatechuic, and $p$-coumaric acids, and flavonoids, such as quercetin, caffeic acid, caffeic acid phenethyl ester, rutin, pinocembrin, apigenin, chrysin, galangin, kaempferol, and isorhamnetin $[35,119,120]$. These compounds influence the grain's visual appearance (pigmentation) and flavor (astringency and bitterness) [121]. However, the composition and antioxidant effect of bee pollen is species-specific, depending strongly on plant source together with biogeographical (regional) origin, ecological habitat, season, and entomological origin $[89,118,120]$. Additionally, beekeepers can introduce other changes to the chemical composition of bee pollen during cleaning, dehydration, packaging, and conservation procedures applied to fresh pollen to increase pollen shelf life $[122,123]$. Collection of this natural product is a relatively recent development, depending primarily on pollen being scraped off bees' legs as they enter the hive [118].

The term "bee bread" refers to the pollen stored by bees in their combs, sealed with a thin layer of honey and beeswax, and matured in a beehive [124,125]. Worker bees use it as food for the larvae, and for the production of royal jelly by young bees [21]. Bees process bee bread for storage by adding various enzymes and honey, resulting in fermentation. This type of lactic acid fermentation renders the end product more digestible, as cell walls are partly destroyed during fermentation [125] and enriched with new nutrients. Its higher free amino acid content and easily assimilated sugars make it more nutritious than bee pollen [124]. One advantage of bee bread is its almost unlimited storability compared with dried or frozen pollen in which nutritional values are rapidly lost [126].

Table 3 summarizes the results of the most recent publications on pollen and bee bread AOA $[6,21,89,118,121,123,124,127-136]$. As indicated for honey, there is usually a positive correlation between TPC, TFC and AOA, but similar TPC and TFC content does not always correspond to similar antioxidant capacity [43,78], as the overall antioxidant capacity of each sample is the result of the combined activity of phenolic and nonphenolic compounds [21]. While honey is more frequently diluted in water for analytical purposes, pollen and bee bread are extracted using large volumes of solvent, then dried and reconstituted to the desired concentration. Ethanolic extraction was found most frequently, followed by methanolic and hydromethanolic extraction. Jin et al. [30] studied the antioxidant properties of water and methanol extract from Linden bee pollen, finding that methanol extract potentiated the antioxidant effect. Borycka et al. [136] compared the results of different extractions using water, ethanol, and methanol, analyzing five types of commercial bee pollen products: bee pellets, micronized bee pellets, pollen tablets, bee bread, and bee bread in honey. They concluded that the extraction method seemed to be crucial and that ethanol was the most effective solvent. TPC and AOA, as determined by FRAP and ABTS assays, was highest in the ethanol extracts taken from each investigated product, followed by methanol and water. Bee bread displayed the highest AOA and phenolic content compared to the other pollen products. Su et al. [132] investigated the AOA of the crude extracts but also different partitioned fractions (petroleum ether, ethyl acetate, $n$-butanol, and water fractions) of different floral sources of bee pollen. Each ethyl acetate fraction of four bee pollens had a higher AOA than the extract and other fractions. Kaškoniene et al. [125] also compared natural with "fermented" pollen to determine the different antioxidant potential of pollen and bee bread, showing that fermentation had a positive effect on antioxidant properties. The increase in biologically active compounds is assumed to be the consequence of partial destruction of the pollen cell walls by bacteria added during fermentation, as occurs naturally in the fermentation of bee bread in the hive. 
Table 3. Summary of the results from studies on antioxidant capacity in pollen and bee bread.

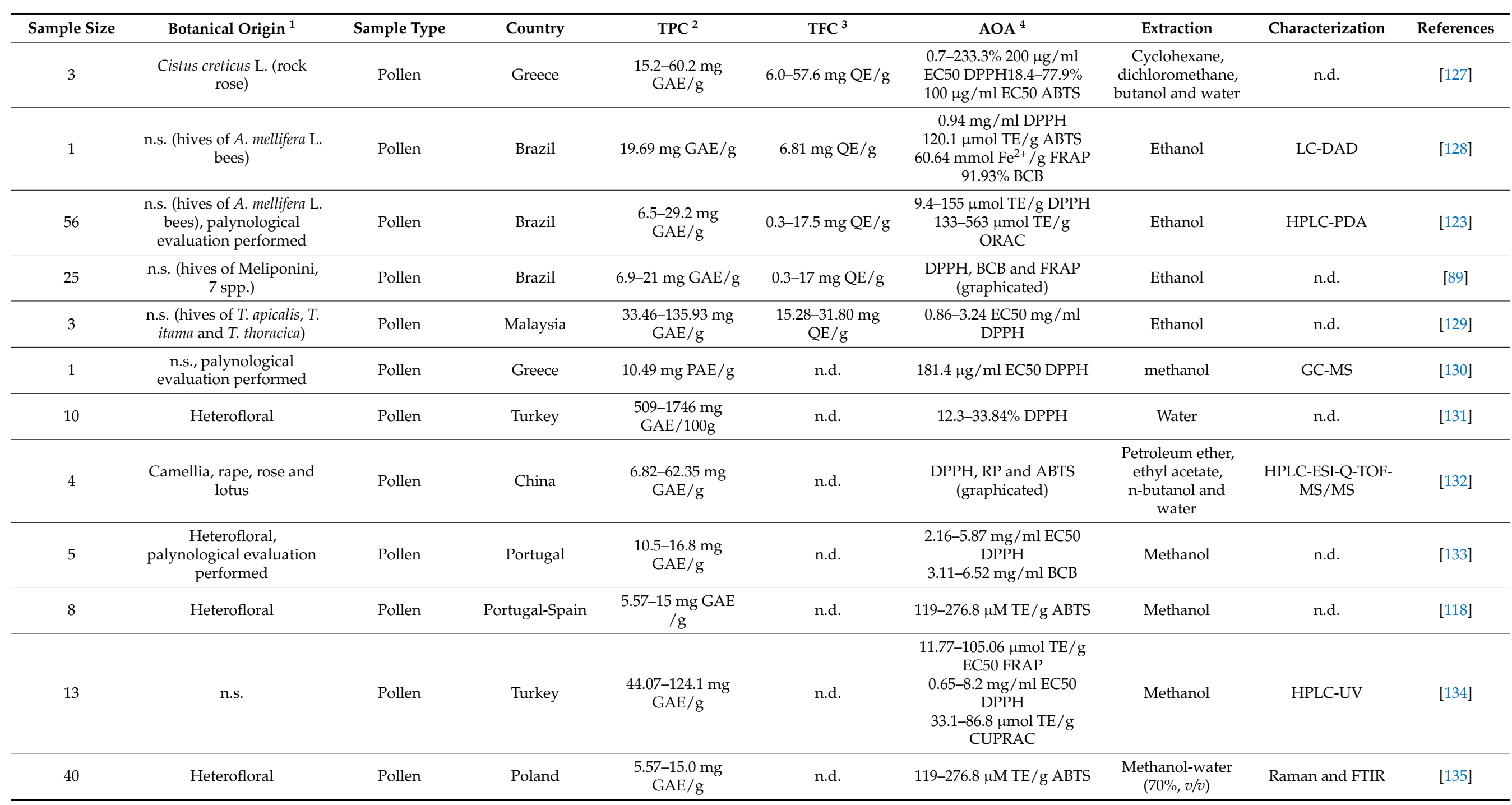


Table 3. Cont.

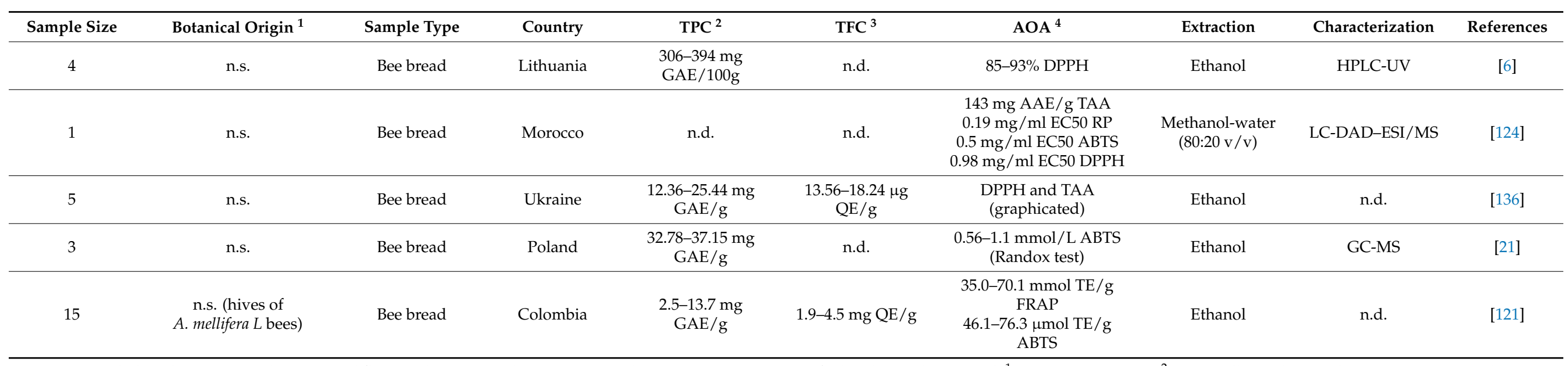

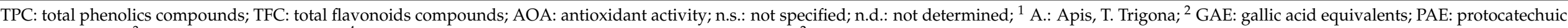
acid equivalents; ${ }^{3} \mathrm{QE}$ : quercetin equivalents; ${ }^{4} \mathrm{AAE}$ : ascorbic acid equivalents; TE: Trolox equivalents; $\mathrm{Fe}^{2+}$ : $\mathrm{FeSO}_{4}{ }^{*} 7 \mathrm{H}_{2} 0$ equivalents. 
Another point of issue is the treatments, such as cleaning, freezing, dehydration, and packaging, that pollen must undergo to best maintain its properties and increase its shelf life prior to sale. De-Melo et al. [119] investigated the effect of using an electric forced-air-circulation oven compared with a lyophilizer on the physical and chemical characteristics of bee pollen, measuring TPC and AOA (with DPPH and ORAC methods), among others. Both parameters were higher in lyophilized samples, which could be related to reactions occurring during heating with air circulation, such as oxidation of some compounds, for example phenols. For pollen conservation purposes, freezing is also to be preferred over dehydration by heat, as natural antioxidants are better preserved [122].

\section{Propolis}

Unlike honey and pollen, propolis (bee glue) is not a food. Bees adopt it as both a building material and a defensive substance. They use it to repair combs, reinforce the thin edges of the honeycomb, but also for its biological action, i.e., as a sealant material to prevent microorganisms (fungi and bacteria) from entering the hive, and to create the most sterile environment known in nature [137]. Moreover, it contains the putrefaction of "embalmed" intruders, killed in the hive but too large to be carried out [3]. To produce propolis, bees collect resinous materials, produced by various botanical processes in different parts of plants, and mix it with wax. It is the bee product with the highest content of specialized plant metabolites (at least $50 \%$ of its weight). It is not therefore surprising that propolis, originating from protective plant secretions and serving as a defensive substance in the beehive, is also active against human pathogens [31].

In general, propolis in nature is composed of 50\% resin and vegetable balsam (including phenolic compounds), 30-40\% wax and fatty acids, 5-10\% essential and aromatic oils, $5 \%$ pollen, and approximately 5\% other substances, including amino acids, micronutrients, and vitamins (thiamin, riboflavin, pyridoxine, vitamins C, and E) [3,138]. Different types of propolis are reported in the literature: i) poplar type (Populus spp., originating mainly from Europe and non-tropical regions of Asia, New Zealand, and North America); ii) birch type (Betula verrucosa, coming from Russia); iii) green type (Baccharis spp., characteristic of Brazil); iv) red type (Dalbergia spp., found in Brazil, Mexico and Cuba); v) Clusia type (from Clusia spp., from Cuba and Venezuela); vi) Pacific type (Macaranga tanarius, originating from Indonesia, Taiwan and Okinawa Prefecture); and vii) (the most recent) Mediterranean type (plants mainly from the Cupressaceae family found in Greece, Sicily, and Malta) [3,139]. Since these types of propolis are classified by their botanical and geographical origins and their climatic zones, their chemical composition and consequently their antioxidant content, will differ.

Table 4 summarizes the results from studies on the antioxidant capacity of propolis [6,32,55,140-157]. The extraction of bioactive compounds depends on the type and quantity of solvent, on temperature and time, and on the process used to interact with raw propolis. The results are often not univocal with respect to the extraction solvent and Table 4 presents the different solvents used and tested for extraction purposes. Among these, a mixture of ethanol and water $(70 / 30$ or $80 / 20)$ is the most commonly used. Preference should be given to this mixture as it is non-toxic and efficient in extracting polyphenols and flavonoids. Miguel et al. [150] compared water, methanol, and 70\% ethanol as extraction solvents, choosing a hydroalcoholic mixture to extract phenols in propolis samples, given its good performance and lower toxicity compared to methanol. Cavalaro et al. [143] also studied the effects of ethanol/water concentration, solid-solvent ratio, and extraction time with regard to the TPC and antioxidant capacity of green Brazilian propolis, using ultrasoundassisted extraction. They optimized the procedure using 99\% ethanol solution and a 1:35 propolis: solvent ratio $(w / v)$, over 20 minutes. Kocot et al. [3] summarized the results of a study on the dependence between the solvent used to extract propolis and bee pollen and their antioxidant properties, reporting that despite numerous differences in composition, propolis extracts always possessed antioxidant properties, even aqueous extracts. 
Table 4. Summary of the results from studies on antioxidant capacity in propolis.

\begin{tabular}{|c|c|c|c|c|c|c|c|c|c|}
\hline $\begin{array}{l}\text { Sample } \\
\text { Size }\end{array}$ & $\begin{array}{c}\text { Botanical } \\
\text { Origin/Bee Species }{ }^{1}\end{array}$ & Propolis Type & Country & TPC $^{2}$ & TFC $^{3}$ & $\mathrm{AOA}^{4}$ & Extraction & Characterization & References \\
\hline 1 & H. itama & n.s. & Brunei & n.d. & n.d. & $\begin{array}{c}12.75-317.65 \mathrm{mg} \mathrm{AAE} / \mathrm{g} \\
\mathrm{DPPH}\end{array}$ & $\begin{array}{l}\text { Ethanol-water mixtures } \\
\text { with different volume } \\
\text { fractions (from } 0.0 \text { to } 1.0) \\
\text { of ethanol }(96 \%) .\end{array}$ & n.d. & [140] \\
\hline 4 & n.s. & n.s. & Lithuania & $\begin{array}{c}211-298 \mathrm{mg} \\
\mathrm{GAE} / 100 \mathrm{~g}\end{array}$ & n.d. & $32-80 \%$ DPPH & Ethanol & HPLC-UV & [6] \\
\hline 2 & n.s. & $\begin{array}{l}\text { green and } \\
\text { brown }\end{array}$ & Brazil & $\begin{array}{l}\text { 31.88-204.30 mg } \\
\text { GAE/g }\end{array}$ & n.d. & $\begin{array}{c}21.50-78.77 \mu \mathrm{g} / \mathrm{mL} \text { EC50 } \\
\text { DPPH }\end{array}$ & $\begin{array}{l}\text { Ethanol- hexane- } \\
\text { dichloromethane }\end{array}$ & GC-MS & [141] \\
\hline 1 & M. orbignyi & n.s. & Brazil & $211 \mathrm{mg} \mathrm{GAE} / 100 \mathrm{~g}$ & $23 \mathrm{mg}$ QE/100g & $40 \mu \mathrm{g} / \mathrm{mL}$ EC50 DPPH & Ethanol $(80 \%)$ & n.d. & [32] \\
\hline 6 & A. mellifera & n.s. & Chile & $\begin{array}{l}1.3-1.6 \mu \mathrm{M} \\
\mathrm{CAE} / \mathrm{mg}\end{array}$ & n.d. & $\begin{array}{c}0-7.3 \mu \mathrm{M} \text { CAE } / \mathrm{mg} \\
\text { ORAC-PGR } \\
\text { 8.9-33.1 } \mu \mathrm{M} \text { CAE } / \mathrm{mg} \\
\text { ORAC-FL } \\
\text { 1.8-3.2 } \mu \mathrm{M} \text { CAE } / \mathrm{mg} \\
\text { FRAP }\end{array}$ & $\begin{array}{c}\text { Ethanol }(90 \%) \text { "wax } \\
\text { free" }\end{array}$ & $\begin{array}{l}\text { HPLC-UV-ESI- } \\
\text { MS/MS }\end{array}$ & [142] \\
\hline 1 & n.s. & green & Brazil & $\begin{array}{l}\text { 57.9-1614.8 mg } \\
\text { GAE/g }\end{array}$ & n.d. & $\begin{array}{c}21.3-13244.5 \mu \mathrm{molTE} / \mathrm{g} \\
\text { ORAC } \\
408.6-13412.1 \mu \mathrm{mol} \mathrm{TE} / \mathrm{g} \\
\text { ABTS }\end{array}$ & $\begin{array}{l}\text { Best using } 99 \% \text { ethanol } \\
\text { solution, 1:35 } \\
\text { propolis:solvent ratio } \\
(\mathrm{w} / \mathrm{v}) \text {, over } 20 \mathrm{~min}\end{array}$ & n.d. & [143] \\
\hline 33 & n.s. & n.s. & Brazil & n.d. & n.d. & $\begin{array}{c}\text { 61.9-1770 } \mu \mathrm{mol} \mathrm{Fe}{ }^{2+} / \mathrm{g} \\
\text { FRAP }\end{array}$ & Ethanol $(80 \%)$ & FTNIR & [144] \\
\hline 1 & n.s. & n.s. & Brazil & n.d. & n.d. & $\begin{array}{c}\text { 14.95-112.12 mg QE/g } \\
\text { DPPH } \\
0-36.28 \mathrm{mg} \mathrm{QE} / \mathrm{g} \beta \text {-carot }\end{array}$ & $\begin{array}{l}\text { Hexane, chloroform, } \\
\text { ethyl acetate and } \\
\text { methanol }\end{array}$ & $\begin{array}{l}\text { GC-EI-MS } \\
\text { HPLC-DAD-ESI- } \\
\text { MS/MS and } \\
\text { NMR }\end{array}$ & [145] \\
\hline 6 & A. mellifera & n.s. & $\begin{array}{c}3 \text { Romania, } 2 \\
\text { Spain, } 1 \text { Honduras }\end{array}$ & 97-442 mg GAE/g & n.d. & n.d. & Ethanol $(70 \%)$ & HPLC-UV & [146] \\
\hline 10 & $\begin{array}{l}\text { M. mondury, } M \text {. } \\
\text { quadrifasciata, } M \text {. } \\
\text { scutellaris, } M \text {. } \\
\text { seminigra, T. angustula }\end{array}$ & n.s. & Brazil & $\begin{array}{l}\text { 32.15-2968.54 mg } \\
\text { GAE/100g }\end{array}$ & n.d. & $\begin{array}{c}176.07-5847.61 \mathrm{mg} \\
\text { AAE/g o 258.24-8582.47 } \\
\text { mg TE/100g DPPH both }\end{array}$ & Ethanol and methanol & n.d. & [147] \\
\hline
\end{tabular}


Table 4. Cont.

\begin{tabular}{|c|c|c|c|c|c|c|c|c|c|}
\hline $\begin{array}{l}\text { Sample } \\
\text { Size }\end{array}$ & $\begin{array}{c}\text { Botanical } \\
\text { Origin/Bee Species }{ }^{1}\end{array}$ & Propolis Type & Country & $\mathrm{TPC}^{2}$ & TFC $^{3}$ & $\mathrm{AOA}^{4}$ & Extraction & Characterization & References \\
\hline 4 & n.s. & n.s. & Portugal & n.d. & n.d. & $\begin{array}{c}14.41-25.24 \mathrm{ug} / \mathrm{mL} \text { EC50 } \\
\text { DPPH } \\
161.73-251.83 \mathrm{ug} / \mathrm{mL} \\
\text { EC50 SOD } \\
118.87-158.14 \mathrm{ug} / \mathrm{mL} \\
\text { EC50 Fe } \mathrm{Fe}^{2+} \text { chel }\end{array}$ & Ethanol & $\begin{array}{l}\text { UPLC-DAD- } \\
\text { ESI/MS }\end{array}$ & [148] \\
\hline 1 & n.s. & n.s. & India & $\begin{array}{l}269.1 \text { and } 159.1 \\
\mathrm{mg} \mathrm{GAE} / \mathrm{g}\end{array}$ & $\begin{array}{c}25.50 \text { and } 57.25 \\
\mathrm{mg} \mathrm{QE} / \mathrm{g}\end{array}$ & $\begin{array}{c}0.05 \text { and } 0.07 \mathrm{mg} / \mathrm{mL} \\
\text { EC50 DPPH }\end{array}$ & Ethanol $(70 \%)$ and water & n.d. & [149] \\
\hline n.s. & n.s. & n.s. & Portugal & $\begin{array}{c}5.28-6.27 \mathrm{mg} \\
\text { Pinocembrin/mL }\end{array}$ & $\begin{array}{c}1.27-1.30 \mathrm{mg} \\
\mathrm{QE} / \mathrm{mL}\end{array}$ & $\begin{array}{c}0.019-0.020 \mathrm{mg} / \mathrm{mL} \text { EC50 } \\
\text { ABTS } \\
0.027-0.031 \mathrm{mg} / \mathrm{mL} \text { EC50 } \\
\text { DPPH } \\
0.034-0.034 \mathrm{mg} / \mathrm{mL} \text { EC50 } \\
\text { SOD } \\
39.5-49.9 \% \mathrm{Fe}^{2+} \text { chel }\end{array}$ & $\begin{array}{l}\text { Methanol, ethanol }(70 \%) \\
\text { and water }\end{array}$ & n.d. & [150] \\
\hline 3 & n.s. & n.s. & Algeria & $\begin{array}{l}15.84-61.63 \mathrm{mg} \\
\text { GAE/100g }\end{array}$ & $\begin{array}{c}124.76-4946.53 \mathrm{mg} \\
\text { CE } / 100\end{array}$ & n.d. & $\begin{array}{c}\text { Water, } 50 \% \text { ethanol, } 85 \% \\
\text { ethanol, } \\
\text { and } 50 \% \text { methanol }\end{array}$ & n.d. & [55] \\
\hline 5 & n.s. & n.s. & Serbia & $\begin{array}{c}1.45-5.31 \mathrm{~g} \\
\text { GAE/100mL }\end{array}$ & n.d. & $0.093-0.346 \%$ EC50 DPPH & Ethanol & n.d. & [152] \\
\hline 48 & n.s. & $\begin{array}{l}\text { Poplar "orange", } \\
\text { "blue" and } \\
\text { "third type" }\end{array}$ & Turkey & $\begin{array}{c}486.9 \text { mg GAE } / \mathrm{g} \\
\text { orange } \\
310.6 \mathrm{mg} \mathrm{GAE} / \mathrm{g} \\
\text { blue } \\
115.7 \mathrm{mg} \mathrm{GAE} / \mathrm{g} \\
\text { third }\end{array}$ & $\begin{array}{c}265.7 \mathrm{mg} \mathrm{QE} / \mathrm{g} \\
\text { orange } \\
185.5 \mathrm{mg} \mathrm{QE} / \mathrm{g} \\
\text { blue } \\
109.53 \mathrm{mg} \mathrm{QE} / \mathrm{g} \\
\text { third }\end{array}$ & $\begin{array}{l}65.64 \% \text { DPPH orange } \\
42.22 \% \text { DPPH blue } \\
26.49 \% \text { DPPH third }\end{array}$ & Ethanol $(80 \%)$ & $\begin{array}{l}\text { UHPLC- } \\
\text { LTQ/orbitrap/ } \\
\text { MS/MS }\end{array}$ & [153] \\
\hline 1 & n.s. & n.s. & India & $\begin{array}{l}\text { 5.15-20.99 mg } \\
\text { GAE/g }\end{array}$ & $\begin{array}{c}8.39-14.26 \mathrm{mg} \\
\mathrm{QE} / \mathrm{g}\end{array}$ & n.d. & Ethanol & HPTLC & [154] \\
\hline
\end{tabular}


Table 4. Cont.

\begin{tabular}{|c|c|c|c|c|c|c|c|c|c|}
\hline $\begin{array}{l}\text { Sample } \\
\text { Size }\end{array}$ & $\begin{array}{c}\text { Botanical } \\
\text { Origin/Bee Species }{ }^{1}\end{array}$ & Propolis Type & Country & TPC $^{2}$ & $\mathrm{TFC}^{3}$ & $\mathrm{AOA}^{4}$ & Extraction & Characterization & References \\
\hline 9 & $\begin{array}{c}\text { A. mellifera, } \\
\text { palynological } \\
\text { identification }\end{array}$ & n.s. & Portugal & $\begin{array}{c}\text { 18.52-277.17 mg } \\
\mathrm{GAE} / \mathrm{mL}\end{array}$ & $\begin{array}{c}\text { 6.34-142.32 mg } \\
\mathrm{CE} / \mathrm{mL}\end{array}$ & n.d. & $\begin{array}{c}\text { Water, methanol:water } \\
(80 \%) \text { and ethanol:water } \\
(80 \%)\end{array}$ & UV-VIS & [155] \\
\hline 5 & n.s. & n.s. & Iraq & $\begin{array}{l}\text { 700-9333 } \mu \mathrm{g} \\
\mathrm{CAE} / \mathrm{mL}\end{array}$ & n.d. & 40.0-83.3\% DPPH & Methanol & HPLC-ESI/MS & [156] \\
\hline 1 & T. itama & n.s. & Malaysia & n.d. & n.d. & 90.7-99.34 \% DPPH & $\begin{array}{l}\text { Subsequent extractions: } \\
\text { hexane, ethyl acetate } \\
\text { and methanol }\end{array}$ & UV-VIS & [157] \\
\hline
\end{tabular}

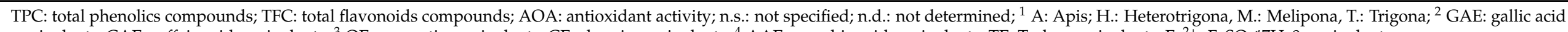

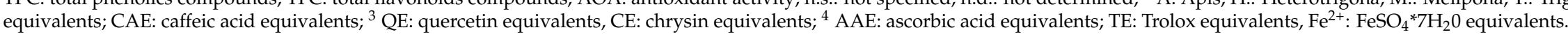


Several studies are underway to define the best extraction procedure: maceration is traditionally used, but in recent years sonication and microwaves have also been recommended on account of their efficiency, time saving potential and selectivity [138]. Ultrasound-assisted extraction, for example, allows many compounds to be extracted in less time (avoiding overnight steps), with fewer organic solvents, and at lower temperatures (which is key to preventing thermal degradation of some active compounds). Attention must also be paid to sonication time (since the ultrasound process can induce degradation of phenols in the sample), which is optimally set at 20-30 minutes [143,146]. The antioxidant properties of other bee products are highly dependent on many factors, such as bee species, plant origin, geographical location, temperature variation, seasonality, and storage conditions $[3,141,147,153]$.

\section{Beeswax}

Worker bees secrete beeswax through wax glands located in the abdomen. Production of this substance generally peaks during the colony growth phase in late spring, and is used to make combs [158]. Beeswax is synthesized starting from honey sugars, and has a crystalline structure suited to hive construction. Chemical composition varies among bee species and geographical zones, and includes hydrocarbons, free fatty acids, and free fatty alcohols, linear wax monoesters, hydroxymonoesters deriving from palmitic, 15hydroxypalmitic and oleic acids, and complex wax esters containing 15-hydroxypalmitic acid and diols [158,159]. Beeswax is used as an additive in different industrial products and processes, as in the food industry, cosmetics, and candles. In pharmaceutical preparations, it is used as a thickener, binder, drug carrier, and a release retardant [35], but several recent studies have reported the therapeutic effects of honeycombs on dental caries and toothache, and other antimicrobial properties [160]. The only studies exploring the AOA of beeswax relate to the by-products of wax recycling and the associated cost-benefit tradeoff. In bee product processing and production, honey, propolis, pollen, and royal jelly are classified as commodities, while honeycomb is discarded as a by-product. Through recycling, beeswax can be transformed into substances previously considered industrial waste, but which could be of great value in biomedicine. This has not yet been adequately explored. Zhao et al. [161] and Giampieri et al. [20,162] did, however, demonstrate that byproducts from beeswax recycling are a rich source of proteins, minerals, and polyphenols, conferring strong total antioxidant capacity, and low levels of toxins. Table 5 summarizes the results of their research on the antioxidant properties of beeswax derivatives. Both research teams affirmed that the antioxidant capacity of wax extracts is higher than that of (some) honey. In Table 5 also royal jelly and bee venom antioxidant properties are considered [20,29,161-166]. 
Table 5. Summary of the results from studies on antioxidant capacity in beeswax, royal jelly and venom.

\begin{tabular}{|c|c|c|c|c|c|c|c|c|c|}
\hline $\begin{array}{l}\text { Sample } \\
\text { Size }\end{array}$ & $\begin{array}{c}\text { Botanical } \\
\text { Origin/Bee Species }{ }^{1}\end{array}$ & Sample Type & Country & TPC $^{2}$ & TFC $^{3}$ & AOA $^{4}$ & Extraction & Characterization & References \\
\hline \multicolumn{10}{|c|}{ Beeswax } \\
\hline 1 & A. mellifera & $\begin{array}{l}\text { Hydro- } \\
\text { ethanolic } \\
\text { extracts of } \\
\text { honeycomb }\end{array}$ & China & $1.62 \mathrm{mg} \mathrm{GAE} / \mathrm{g}$ & $\begin{array}{c}1.62 \mathrm{mg} / \mathrm{g} \\
\text { (equivalent n.s.) }\end{array}$ & $\begin{array}{c}5.91 \mathrm{mg} / \mathrm{ml} \mathrm{EC50} \\
\text { DPPH } \\
1.33 \mathrm{mg} \mathrm{TE} / \mathrm{g} \text { FRAP } \\
0.38 \mathrm{mg} \mathrm{Na} 2 \text { EDTA } / \mathrm{g} \\
\mathrm{Fe}^{2+} \text { chel. }\end{array}$ & Ethanol 75\% & GC-MS & [161] \\
\hline 10 & A. mellifera & $\begin{array}{l}\text { Waste sediment } \\
\text { separated from } \\
\text { wax (5 MUD1 } \\
\text { and } 5 \text { MUD2) }\end{array}$ & n.s. & $\begin{array}{c}1435.66 \text { and } 432.66 \\
\text { mg GAE/100g }\end{array}$ & $\begin{array}{l}295.84 \text { and } 142.17 \\
\mathrm{mg} \mathrm{CE} / 100 \mathrm{~g}\end{array}$ & $\begin{array}{c}1.60 \text { and } 0.23 \mathrm{mM} \mathrm{TE} \\
\text { TEAC } \\
1.93-0.59 \mathrm{mM} \text { TE FRAP }\end{array}$ & $\begin{array}{l}\text { Sediment with inorganic and } \\
\text { organic waste was separated } \\
\text { from wax honeycombs } \\
\text { during recycling process } \\
\text { following a heating process } \\
\text { by steam (MUD1); the } \\
\text { remaining wax was passed } \\
\text { to a continuous decanter, } \\
\text { where a fine sediment was } \\
\text { generated (MUD2). }\end{array}$ & $\begin{array}{l}\text { UPLC-DAD/ESI- } \\
\text { MS }\end{array}$ & {$[20,162]$} \\
\hline \multicolumn{10}{|c|}{ Royal jelly } \\
\hline 1 & A. mellifera & $\begin{array}{l}\text { Recombinant } \\
\text { MRJPs 1-7 }\end{array}$ & South Korea & n.d. & n.d. & $\begin{array}{c}\text { DPPH (about } \\
\text { 30-80\%-graphicated) }\end{array}$ & n.s. & n.d. & [29] \\
\hline 28 & A. mellifera & $\begin{array}{l}19 \text { local and } 9 \\
\text { commercial RJ }\end{array}$ & Romania & $\begin{array}{c}23.49 \text { and } 23.25 \\
\mathrm{mg} \mathrm{GAE} / \mathrm{g}\end{array}$ & n.d. & $\begin{array}{c}37.23 \text { and } 35.94 \% \mathrm{DPPH} \\
2.20 \text { and } 1.83 \mathrm{mM} \\
\mathrm{Fe}^{2+} / \mathrm{g} \text { FRAP }\end{array}$ & Water $10 \%(\mathrm{w} / \mathrm{v})$ & n.d. & [163] \\
\hline \multicolumn{10}{|c|}{ Venom } \\
\hline 1 & A. mellifera syriaca & Venom & Lebanon & n.d. & n.d. & $\begin{array}{l}50-86.6 \% \mathrm{DPPH} \text { (from } \\
2.5 \text { to } 500 \mu \mathrm{g} / \mathrm{mL} \text { ) }\end{array}$ & $\begin{array}{l}\text { Lyophilized crude venom } \\
\text { dissolved in } 1 \mathrm{~mL} \text { water (5 } \\
\mathrm{mg} / \mathrm{mL} \text { ) }\end{array}$ & LC-ESI-MS & [164] \\
\hline 5 & A. mellifera iberiensis & Venom & Portugal & n.d. & n.d. & $\begin{array}{c}346-512 \mu \mathrm{g} / \mathrm{mL} \text { EC50 } \\
\mathrm{DPPH} \\
238-326 \mu \mathrm{g} / \mathrm{mL} \text { EC50 } \\
\mathrm{RP} \\
435-826 \mu \mathrm{g} / \mathrm{mL} \text { EC50 } \\
\mathrm{BCB}\end{array}$ & Water $(\mathrm{mg} / \mathrm{mL})$ & LC/DAD/ESI-MS & [165] \\
\hline 4 & $\begin{array}{l}\text { A. mellifera, A. cerana, } \\
\text { A. florea, A. dorsata }\end{array}$ & Venom & Thailand & n.d. & n.d. & $\begin{array}{c}\text { DPPH, FRAP and ABTS } \\
\text { (graphicated) }\end{array}$ & $\begin{array}{l}\text { Various concentrations in } \\
\text { PBS }\end{array}$ & HPLC-UV & [166] \\
\hline
\end{tabular}

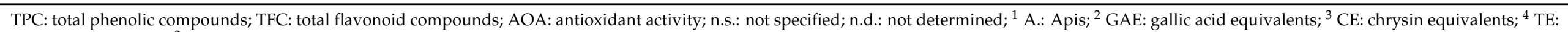
Trolox equivalents; $\mathrm{Fe}^{2+}$ : $\mathrm{FeSO}_{4}{ }^{*} 7 \mathrm{H}_{2} \mathrm{O}$ equivalents. 


\section{Royal Jelly}

Royal jelly is a substance secreted by the hypopharyngeal and mandibular glands of worker honeybees. It is a yellowish, creamy, acidic substance with a slightly pungent odor and taste composed, on a wet weight basis, of water $(60-70 \%)$, proteins $(9-18 \%)$, sugars (7-18\%)-mainly fructose, glucose and sucrose-lipids (3-8\%), minerals $(0.8-3.0 \%)$, ash $(0.8-3 \%)$, and traces of polyphenols and vitamins [163]. Royal jelly is fed to all bee larvae in the early stages of life and to the queen bee until she dies. It plays a crucial role in determining the caste of honeybees because larvae fed with greater amounts of royal jelly for a longer period develop into large, fertile, long-living queens rather than smaller, infertile, short-living workers [167]. Royal jelly has been proven to have numerous functional properties such as disinfectant action, and antibacterial, anti-inflammatory, vasodilative, hypotensive, antihypercholesterolemic, antitumor, and antioxidant activity, as reported in the review by Ramadan and Al-Ghamdi [168]. The antioxidant potency of royal jelly is attributed to its polyphenolic and flavonoid compounds; free amino acids, including essential ones; small peptides, such as di-peptides (Lys-Tyr, Arg-Tyr, and Tyr-Tyr) obtained from protease hydrolyzed royal jelly proteins; peptides and proteins; fatty acids (the main being 10-hydroxydecanoic acid); and vitamins [3,162,169]. The principal flavonoids present in royal jelly include flavonoles (e.g., quercetin, kaempherol, galangin, and fisetin), flavanones (e.g., pinocembrin, naringin, and hesperidin), and flavones (e.g., apigenin, acacetin, chrysin, and luteolin) [168]. Major royal jelly proteins (MRJPs) represent $83-90 \%$ of the protein component of royal jelly and are composed of nine known members with molecular weights of between 49 and $87 \mathrm{kDa}[28,167]$. Table 5 summarizes the results of the most recent studies on the antioxidant properties of royal jelly and its derivatives. Using a DPPH radical-scavenging assay, Park et al. [29] confirmed the antioxidant capacity of MRJPs 1-7 of A. mellifera at levels ranging between approximately 30 and $80 \%$ of residual radical. Pavel et al. [162] quantified TPC and AOA in local (Romanian) and commercial royal jelly (10\% in distilled water). TPC was measured by a Folin-Ciocalteu reagent reduction and found to be 23.49 and $23.25 \mathrm{mg} \mathrm{GAE} / \mathrm{g}$ for local and commercial royal jelly, respectively. Antioxidant capacity was determined using DPPH radical scavenging and FRAP assays, resulting in 37.23 and $35.94 \%$ inhibition and 2.20 and $1.83 \mathrm{mM} \mathrm{Fe}^{2+} / \mathrm{g}$, respectively. Hence, no major differences were found between the two types of royal jelly. There is a paucity of data in the literature on the polyphenolic content and AOA of royal jelly, and existing data are not very recent. TPC values ranged from 21.2 to $22.8 \mathrm{mg} / \mathrm{g}$ of powder lyophilized from water and alkaline extracts [170], and from 150 to $219 \mu \mathrm{g} / \mathrm{g}$ for different royal jelly samples [171]. However, the data are not comparable as different extracts and different formulations of royal jelly were used (fresh or lyophilized). While the polyphenolic content and AOA of royal jelly do appear to be highly variable, new targeted studies are nonetheless warranted. Conversely, several in vivo studies in animal models and humans have been performed showing the antioxidant potential of this functional food, as reviewed in Kunugi et al. [169] and Sığ et al. [172].

\section{Bee Venom}

Bee venom, or apitoxin, is a mixture of several components with proven therapeutic benefits. The main components are peptides, such as melittin (which is also the main component of bee venom) and apamin, and proteins (enzymes), followed by low molecular compounds, including phospholipids, biogenic amines (such as histamine and catecholamines), amino acids, sugars, volatiles (pheromones), and minerals $[35,173]$. Bees use their venom as a defense tool against predators, intruders, and for colony defense, but the healing properties of bee stings have been known since ancient times [174]. Evidence has recently been found to support these medical claims in numerous studies and the use of bee venom is applied in different conditions with various patho-physiological substrates, including for the nervous, immune, or cardiovascular systems [163].

As shown in Table 5, only three recent studies have quantified the AOA of bee venom using classical assays. All samples revealed antioxidant properties, which were apparently 
unrelated to any of the individual components identified and quantified in the same samples. Some data suggest that melittin alone exerts very poor AOA compared to bee venom extracts and this might be due to the influence of other venom components [163]. Hence, some other minor compounds, together with synergistic/antagonistic effects at specific concentrations, could be involved in the reported bioactivities, contributing to different results among bee venom samples [164,165].

As in the case of royal jelly, several publications can be found on studies of AOA of bee venom in vivo in animal models and humans [174-179], and in vitro in cell cultures, as shown in Table 6. 
Table 6. In vitro antioxidant properties of bee products.

\begin{tabular}{|c|c|c|c|c|c|}
\hline Bee Product & Bees Species $^{1}$ & Cell culture/Substrate & Antioxidant Activity & Measurement & References \\
\hline \multicolumn{6}{|c|}{ Honey } \\
\hline Monofloral honeys (Italy) & A. mellifera & Bovine brain microsomes & Peroxyl-radical scavenging capacity & $\begin{array}{l}\text { Time-course of TBA-RS formation during } \\
\text { microsomal oxidation }\end{array}$ & [74] \\
\hline $\begin{array}{l}\text { Commercial multifloral } \\
\text { honey (Italy) }\end{array}$ & A. mellifera & $\begin{array}{l}\text { Human endothelial cell line } \\
\text { (EA.hy926) }\end{array}$ & $\begin{array}{c}\text { Cell membrane oxidation, intracellular oxidative } \\
\text { damage, cell viability using MTT } \\
\text { [3-(4,5-dimethyl-2-thiazolyl) -2,5-diphenyl -2H- } \\
\text { tetrazolium bromide] assay and GSH analysis }\end{array}$ & $\begin{array}{l}\text { Cytoprotective activity by fluorimetric } \\
\text { determination, cell viability (the absorbance is } \\
\text { proportional to the number of living cells) and } \\
\text { microscopic evaluation }\end{array}$ & [16] \\
\hline $\begin{array}{l}\text { Buckwheat and Manuka } \\
\text { honeys }\end{array}$ & n.s. & $\begin{array}{l}\text { HepG2 cell lines, Cell Bank of } \\
\text { Institute of the Biochemistry and } \\
\text { Cell Biology, Chinese Academy } \\
\text { of Sciences, Shanghai, China }\end{array}$ & $\begin{array}{l}\text { Cellular antioxidant activity (CAA) and } \\
\text { cytotoxicity assay }\end{array}$ & $\begin{array}{c}\text { Peroxyl radical-induced oxidation of DCFH to DCF } \\
\text { by fluorimetric determination and inhibition of } \\
\text { oxidation by honey extracts (microscopic } \\
\text { evaluation) }\end{array}$ & [17] \\
\hline Malaysian kelulut honey & Trigona spp. & $\begin{array}{l}\text { Lymphoblastoid cell line (LCL), } \\
\text { AGRE, Los Angeles, CA, USA }\end{array}$ & $\begin{array}{l}\text { Ferric-reducing antioxidant potential assay, } \\
\text { total phenolic, and flavonoid content by UV } \\
\text { spectrophotometry. Cell viability using MTS assay }\end{array}$ & $\begin{array}{l}\text { Cell viability (\%) reading the absorbance at } 490 \mathrm{~nm} \\
\text { and positively affected by antioxidant properties }\end{array}$ & [18] \\
\hline Monofloral honeys (China) & A. dorsata & $\begin{array}{l}\text { HepG2 cell lines, Stem Cell Bank } \\
\text { of Chinese Academy of Sciences }\end{array}$ & Cellular antioxidant activity (CAA) assay & $\begin{array}{l}\text { Effective reduction of intracellular oxidative state } \\
\text { reacting with peroxyl radicals or ROS/RNS. } \\
\text { Fluorimetric determination }\end{array}$ & [19] \\
\hline \multicolumn{6}{|c|}{ Beeswax } \\
\hline $\begin{array}{l}\text { Two beeswax recycling } \\
\text { by-products (MUD1 and } \\
\text { MUD2) }\end{array}$ & A. mellifera & $\begin{array}{l}\text { Adult skin HDF, GIBCO } \\
\text { Invitrogen cell, Waltham, MA, } \\
\text { USA }\end{array}$ & $\begin{array}{l}\text { ROS concentration using CellROX }{ }^{\circledR} \text { Orange } \\
\text { Reagent applied according to manufacturer's } \\
\text { instructions }\end{array}$ & $\begin{array}{l}\text { Intracellular ROS: percentage of cells with } \\
\text { increased ROS levels related to the control }\end{array}$ & [161] \\
\hline \multicolumn{6}{|c|}{ Pollen } \\
\hline Bee pollen (China) & n.s. & Blood from male Kunming mice & $\begin{array}{l}\text { Superoxide dismutase (SOD) assay, } \\
\text { lipid peroxidation index assay and total } \\
\text { antioxidant capacity (T-AOC) assay }\end{array}$ & $\begin{array}{c}\text { Spectrophotometric measurement of SOD content } \\
(\mathrm{U} / \mathrm{mL}), \text { MDA content }(\mathrm{nmol} / \mathrm{mL}) \text { and inhibition } \\
\text { rate }(\%)\end{array}$ & [30] \\
\hline $\begin{array}{l}\text { Bee pollen from Jara } \\
\text { pringosa (Sistus ladanifer) } \\
\text { and Jara blanca (Cistus } \\
\text { albidus) (Spain) }\end{array}$ & A. mellifera & $\begin{array}{l}\text { Retinal ganglion cells (RGC-5, } \\
\text { a rat ganglion cell-line } \\
\text { transformed using E1A virus) }\end{array}$ & $\begin{array}{l}\text { Antioxidant-capacity assay-measured the radicals } \\
\text { induced in RGC- } 5 \text { by the application of } \operatorname{ROS}\left(\mathrm{H}_{2} \mathrm{O}_{2} \text {, }\right. \\
\left.\qquad \mathrm{O}_{2}^{\bullet-} \text {, and } \mathrm{HO}\right)\end{array}$ & $\begin{array}{l}\text { Intracellular ROS: time-kinetic and } \\
\text { concentration-response data for bee pollen towards } \\
\text { production of various ROS in term of fluorescence } \\
\text { intensity }\end{array}$ & [22] \\
\hline
\end{tabular}


Table 6. Cont.

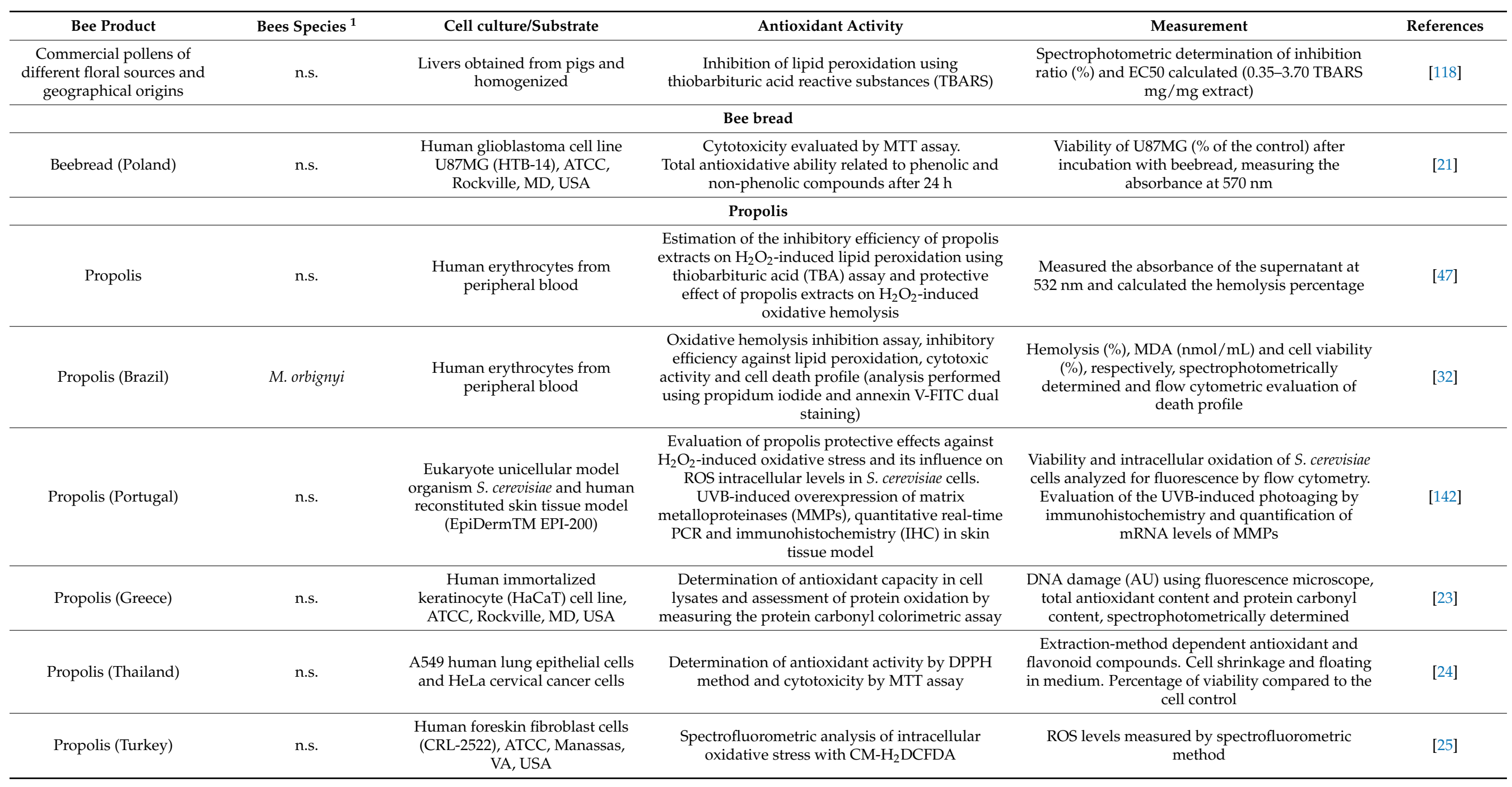


Table 6. Cont.

\begin{tabular}{|c|c|c|c|c|c|}
\hline Bee Product & Bees Species $^{1}$ & Cell culture/Substrate & Antioxidant Activity & Measurement & References \\
\hline $\begin{array}{l}\text { Brazilian green propolis } \\
\text { from Baccharis } \\
\text { dracunculifolia (Minas } \\
\text { Gerais State, Brazil) }\end{array}$ & A. mellifera & $\begin{array}{l}\text { Retinal ganglion cells (RGC-5, } \\
\text { a rat ganglion cell-line } \\
\text { transformed using E1A virus) }\end{array}$ & $\begin{array}{l}\text { Antioxidant-capacity assay measured the radicals } \\
\text { induced in RGC-5 by the application of ROS } \\
\text { (H2O2, O2--, and } \mathrm{HO})\end{array}$ & $\begin{array}{c}\text { Intracellular ROS: time-kinetic and } \\
\text { concentration-response data for propolis towards } \\
\text { production of various ROS in terms of fluorescence } \\
\text { intensity }\end{array}$ & [22] \\
\hline Red propolis (Brazil) & n.s. & $\begin{array}{l}\text { Human tumor cell lines HL-60 } \\
\text { (leukemia), PC3 (prostate } \\
\text { carcinoma), SNB19 } \\
\text { (glioblastoma), and HCT-116 } \\
\text { (colon carcinoma), National } \\
\text { Cancer Institute, USA }\end{array}$ & $\begin{array}{l}\text { High in vitro antioxidant activity related to total } \\
\text { phenolic and flavonoid compound content. } \\
\text { MTT assay to determine the cytotoxic (antitumor) } \\
\text { potential of the extracts }\end{array}$ & $\begin{array}{l}\text { Growth inhibition of tumor cell lines (\%), } \\
\text { using spectrophotometer }\end{array}$ & [26] \\
\hline Propolis (Cameroon) & n.s. & $\begin{array}{l}\text { Diluted human whole blood, } \\
\text { mouse macrophage cell line } \\
\text { J774.2, European Collection of } \\
\text { Cell Cultures (UK) and NIH-3 T3 } \\
\text { fibroblast cells, ATCC, Manassas, } \\
\text { USA }\end{array}$ & $\begin{array}{c}\text { Oxidative burst assay (luminol-enhanced } \\
\text { chemiluminescence assay), nitric oxide assay and } \\
\text { MTT cytotoxicity assay }\end{array}$ & $\begin{array}{l}\text { ROS inhibition }(\mathrm{EC} 50 \mu \mathrm{g} / \mathrm{mL}), \text { NO inhibition } \\
(\mathrm{EC} 50 \mu \mathrm{g} / \mathrm{mL}) \text { and cytotoxicity }(\mathrm{EC} 50 \mu \mathrm{g} / \mathrm{mL}) \\
\text { respectively, using spectrophotometer }\end{array}$ & [33] \\
\hline Propolis (Morocco) & n.s. & $\begin{array}{c}\text { Human monocytic cell line } \\
\text { THP-1 (ATCC 202-TIB), } \\
\text { human colorectal carcinoma cell } \\
\text { line HCT-116 (ATCC } \\
\text { CCL-247 } \\
\text { line MCF-7 } \text { (ATCC breast cancer cell } \\
\text { HTB-22 }^{\mathrm{TM}} \text { ) }\end{array}$ & $\begin{array}{l}\text { High antioxidant content and activity by } \\
\text { scavenging free radicals with IC50 }(\mathrm{DPPH}=0.02, \\
\text { ABTS }=0.04, \text { and FRAP }=0.04 \mathrm{mg} / \mathrm{ml}) . \text { MTT assay } \\
\text { for cytotoxic and cytostatic activity and cell } \\
\text { viability determination }\end{array}$ & $\begin{array}{c}\text { Total phenols, flavone, and flavonol and } \\
\text { antioxidant activity affect cell viability defined as } \\
\text { the ratio (\%) of absorbance of treated cells to } \\
\text { untreated cells (control) }\end{array}$ & [27] \\
\hline Propolis (Poland) & n.s. & $\begin{array}{l}\text { Fresh human erythrocyte } \\
\text { concentrates }(65 \%), \text { Blood bank } \\
\text { in Poznan, Poland }\end{array}$ & $\begin{array}{l}\text { High antioxidant potential related to DPPH } \\
\text { free-radical scavenging activity and reducing } \\
\text { power; significant protection of human red blood } \\
\text { cells from oxidative damage. Hemolysis assays }\end{array}$ & $\begin{array}{l}\text { Hemolysis (\%) estimated by measuring absorbance } \\
\text { of the supernatant; microscope studies of } \\
\text { erythrocyte shape transformation (Bessis } \\
\text { classification) and inhibition of } \\
\text { free-radical-induced hemolysis }\end{array}$ & [34] \\
\hline \multicolumn{6}{|c|}{ Royal jelly } \\
\hline $\begin{array}{l}\text { Enzyme-treated royal jelly } \\
\text { (Jiangshan, China) }\end{array}$ & A. mellifera & $\begin{array}{l}\text { Peritoneal macrophages, BALB/c } \\
\text { mice }\end{array}$ & $\begin{array}{l}\text { Cell viability MTT assay and ROS, SOD and GSH } \\
\text { quantification according to the manufacturer's kit } \\
\text { instructions }\end{array}$ & $\begin{array}{c}\text { Intracellular ROS and NO production; activity of } \\
\text { the enzyme SOD and concentration of the } \\
\text { antioxidant GSH (spectrophotometric } \\
\text { quantification) }\end{array}$ & [180] \\
\hline $\begin{array}{l}\text { Fresh royal jelly from } \\
\text { Yangtze Valley, People's } \\
\text { Republic of China }\end{array}$ & A. mellifera & $\begin{array}{l}\text { Retinal ganglion cells (RGC-5, } \\
\text { a rat ganglion cell-line } \\
\text { transformed using E1A virus) }\end{array}$ & $\begin{array}{l}\text { Antioxidant-capacity assay measured the radicals } \\
\text { induced in RGC- } 5 \text { by the application of } \mathrm{ROS}\left(\mathrm{H}_{2} \mathrm{O}_{2} \text {, }\right. \\
\left.\qquad \mathrm{O}_{2} \cdot^{-} \text {, and } \mathrm{HO}\right)\end{array}$ & $\begin{array}{c}\text { Intracellular ROS: time-kinetic and } \\
\text { concentration-response data for royal jelly towards } \\
\text { production of various ROS in terms of fluorescence } \\
\text { intensity }\end{array}$ & [22] \\
\hline
\end{tabular}


Table 6. Cont

\begin{tabular}{|c|c|c|c|c|c|}
\hline Bee Product & Bees Species $^{1}$ & Cell culture/Substrate & Antioxidant Activity & Measurement & References \\
\hline $\begin{array}{l}\text { Fresh royal jelly (Korea) } \\
\text { and recombinant AcMRJP2 } \\
\text { protein }\end{array}$ & A. cerana & $\begin{array}{c}\text { Murine fibroblast cell line NIH } 3 \\
\text { T3 }\end{array}$ & $\begin{array}{l}\text { Antioxidant activity and shielding of the cell } \\
\text { against oxidative stress and DNA protection } \\
\text { against ROS. Cell viability measured by MTT assay, } \\
\text { apoptosis assay and DNA protection assay }\end{array}$ & $\begin{array}{c}\text { Antioxidant activity determines increased cell } \\
\text { viability (\%), reduced caspase-3 activity and } \\
\text { apoptosis in the cells using laser-scanning confocal } \\
\text { microscopy. DNA nicking assay in a } \\
\text { metal-catalyzed oxidation system observed by } \\
\text { agarose gel electrophoresis }\end{array}$ & [28] \\
\hline $\begin{array}{l}\text { Recombinant AmMRJPs } \\
1-7\end{array}$ & A. mellifera & $\begin{array}{c}\text { Murine fibroblast cell line NIH } 3 \\
\text { T3 }\end{array}$ & $\begin{array}{c}\text { Radical scavenging activity and protection against } \\
\text { DNA oxidative damage. Cell viability measured by } \\
\text { MTT assay, apoptosis assay and DNA protection } \\
\text { assay }\end{array}$ & $\begin{array}{c}\text { Antioxidant activity determines increased cell } \\
\text { viability (\%), reduced caspase-3 activity and } \\
\text { apoptosis in the cells using laser-scanning confocal } \\
\text { microscopy. DNA nicking assay in a } \\
\text { metal-catalyzed oxidation system observed by } \\
\text { agarose gel electrophoresis }\end{array}$ & [29] \\
\hline \multicolumn{6}{|c|}{ Bee Venom } \\
\hline $\begin{array}{l}\text { Melittin (Northeast } \\
\text { Portugal) }\end{array}$ & A. mellifera iberiensis & $\begin{array}{l}\text { MCF-7, NCI-H460, HeLa and } \\
\text { HepG2 tumour lines }\end{array}$ & $\begin{array}{l}\text { Free-radical scavenging activity, reducing power, } \\
\text { lipid peroxidation inhibition and high capacity to } \\
\text { inhibit NO production. }\end{array}$ & $\begin{array}{c}\text { Chemical characterization by LC/DAD/ESI-MS; } \\
\text { DPPH for free-radical scavenging activity; } \\
\text { reducing power measuring the absorbance at } \\
690 \mathrm{~nm}\end{array}$ & [165] \\
\hline
\end{tabular}

${ }^{1}$ A: Apis; M.: Melipona; n.s.: not specified. 


\section{In Vitro Determination of AOA}

Different studies have been carried out to determine in vitro the AOA of bee products using biological (cellular) systems. The more recent ones are summarized in Table 6 $[16-30,32-34,47,74,118,142,161,165,180]$. Cell lines of different types and origins have, in the main, been used for this purpose in all bee products. Propolis was the most widely tested. The various systems adopted performed well in determining the AOA of bee products and different analytical methods from the ones reported in Table 1 were applied. In addition, other effects of bee products on cell lines and in in vitro systems have also been tested in parallel but are beyond the scope of this review.

\section{Concluding Remarks}

The antioxidant properties of different bee products can be only be compared when the data are obtained using the same methods and units of measurement for the different matrices. Bartkiene et al. [6] compared honey, propolis, and bee bread, ranking TPC and AOA values (measured as \% DPPH) in the following order: bee bread > propolis > honey, and bee bread > honey $>$ propolis, respectively. Based on data from the literature, propolis should be the most powerful antioxidant of bee products-having been shown to contain the highest levels of phenols and flavonoids—-followed by pollen and royal jelly [3,35]. The results do, however, differ considerably depending on matrix, extraction solvent, and assay. By way of example, Nakajima et al. [22] (using an antioxidant-capacity assay to measure the radicals induced in a rat cell line through application of ROS) observed the rank order of antioxidant effects to be as follows: propolis water extract > propolis ethanol extract $>$ pollen, but neither royal jelly nor 10-hydroxy-2-decenoic acid (10-HDA) had any effect. A comparative study of the AOA of honey and propolis performed by Mouhoubi-Tafinine et al. [55] showed propolis samples to have higher concentrations of polyphenols, flavonoids, vitamin C, and carotenoids, and to display a greater AOA (measured by the reducing power assay). Even compared to pollen, honey clearly appears to have lower phenol and AOA levels, as shown by Duarte et al. [89] Mohdaly et al. [181] reported that propolis extract had superior scavenging activity (based on DPPH and ABTS assays) compared to pollen extract. The disparity of the results presented in this review is well known to be influenced by considerable botanical, geographical, and other above-mentioned differences among samples. There are many inconsistencies in the information related to AOA analysis of bee products, such as sample dilution, extraction method, and conditions, quantification method, and criteria for reporting the results. All these have a decisive influence on the disparity of results, hindering comparison of the biological properties of different samples of the same bee products, despite being similar. Hence, to determine valid common criteria, the analytical procedures need to be as standardized as possible to accurately classify bee products by composition and commercial value. It is difficult to compare the analytical results reported in this review with each other, because even where the same analytical technique is used (as the Folin-Ciocalteu method), the results may be expressed in different units. Results are calculated by plotting the concentration of a calibration standard against absorbance on a standard curve, but analytical results can only be compared with others when the same reference compounds are used. Furthermore, bee products are chemically very complex, and the use of solvents of different polarity affects the composition of the solutions or extracts to be analyzed. While hydrophilic substances are more soluble in polar solvents such as alcohols, hydrophobic ones show greater affinity for non-polar solvents such as hydrocarbons. The analytical result can therefore also vary according to the solvent used to dissolve the honey or propolis or other hive products being tested. The extract's properties strongly depend on the solvent used but also on extraction conditions, time, and temperature [3]. Accurate standardization of analytical methods is needed to define quality criteria and support estimation of the commercial value of these expensive natural products. Working with standardized methodologies, accepted by researchers and analytical laboratories, with adequate analytical protocols that define the solvents, extraction procedures, and criteria for expressing the results, will allow the collection of reliable, comparable data. 
Author Contributions: Conceptualization, M.M., and F.M.; project administration, F.M.; writingoriginal draft, M.M.; writing - review and editing, M.M. and F.M. All authors have read and agreed to the published version of the manuscript.

Funding: This research received no external funding.

Acknowledgments: The English text was edited by Joanne M. Fleming.

Conflicts of Interest: All the authors declare that there is no conflict of interest.

\section{References}

1. Crane, E. Bees and Beekeeping-Science, Practice and World Resources; Heinemann Newnes: Oxford, UK, $1990 ;$ p. 614.

2. Bogdanov, S. Honey in medicine: A review. Bee Prod. Sci. 2017, 28. Available online: http://www.bee-hexagon.net/ (accessed on 10 October 2020).

3. Kocot, J.; Kiełczykowska, M.; Luchowska-Kocot, D.; Kurzepa, J.; Musik, I. Antioxidant potential of propolis, bee pollen, and royal jelly: Possible medical application. Oxid. Med. Cell. Longev. 2018, 2, 7074209. [CrossRef] [PubMed]

4. Kieliszek, M.; Piwowarek, K.; Kot, A.M.; Błażejak, S.; Chlebowska-Śmigiel, A.; Wolska, I. Pollen and bee bread as new healthoriented products: A review. Trends Food Sci. Tech. 2018, 71, 170-180. [CrossRef]

5. Badolato, M.; Carullo, G.; Cione, E.; Aiello, F.; Caroleo, M.C. From the hive: Honey, a novel weapon against cancer. Eur. J. Med. Chem. 2017, 142, 290-299. [CrossRef] [PubMed]

6. Bartkiene, E.; Lele, V.; Sakiene, V.; Zavistanaviciute, P.; Zokaityte, E.; Dauksiene, A.; Jagminas, P.; Klupsaite, D.; Bliznikas, S.; Ruzauskas, M. Variations of the antimicrobial, antioxidant, sensory attributes and biogenic amines content in Lithuania-derived bee products. LWT Food Sci. Technol. 2020, 118, 108793. [CrossRef]

7. Viuda-Martos, M.; Ruiz-Navajas, Y.; Fernández-López, J.; Pérez-Alvarez, J.A. Functional properties of honey, propolis, and royal jelly. J. Food Sci. 2008, 73, R117. [CrossRef] [PubMed]

8. Küçük, M.; Karaoğlu, S.; Ulusoy, E.; Baltacı, C.; Candan, F. Biological activities and chemical composition of three honeys of different types from Anatolia. Food Chem. 2007, 100, 526-534. [CrossRef]

9. Di Marco, G.; Gismondi, A.; Panzanella, L.; Canuti, L.; Impei, S.; Leonardi, D.; Canini, A. Botanical influence on phenolic profile and antioxidant level of Italian honeys. J. Food Sci. Technol. 2018, 55, 4042-4050. [CrossRef]

10. Tahir, H.E.; Xiaobo, Z.; Zhihua, L.; Jiyong, S.; Zhai, X.; Wang, S.; Mariod, A.A. Rapid prediction of phenolic compounds and antioxidant activity of Sudanese honey using Raman and Fourier transform infrared (FT-IR) spectroscopy. Food Chem. 2017, 226, 202-211. [CrossRef]

11. Di Marco, G.; Manfredini, A.; Leonardi, D.; Canuti, L.; Impei, S.; Gismondi, A.; Canini, A. Geographical, botanical and chemical profile of monofloral Italian honeys as food quality guarantee and territory brand. Plant Biosyst. 2016, 151, 450-463. [CrossRef]

12. Ávila, S.; Beuxa, M.R.; Hoffmann Ribania, R.; Zambiazi, R.C. Stingless bee honey: Quality parameters, bioactive compounds, healthpromotion properties and modification detection strategies. Trends Food Sci. Tech. 2018, 81, 37-50. [CrossRef]

13. Popova, M.; Trusheva, B.; Bankova, V. Propolis of stingless bees: A phytochemist's guide through the jungle of tropical biodiversity. Phytomed. 2019, 27, 153098. [CrossRef]

14. Biluca, F.C.; de Gois, J.S.; Schulz, M.; Braghini, F.; Gonzaga, L.V.; Maltez, H.F.; Rodrigues, E.; Vitali, L.; Micke, G.A.; Borges, D.L.G.; et al. Phenolic compounds, antioxidant capacity and bioaccessibility of minerals of stingless bee honey (Meliponinae). J. Food Comp. Anal. 2017, 63, 89-97. [CrossRef]

15. Temaru, E.; Shimura, S.; Amano, K.; Karasawa, T. Antibacterial activity of honey from stingless honeybees (Hymenoptera; Apidae; Meliponinae). Pol. J. Microbiol. 2007, 56, 281-285. [PubMed]

16. Beretta, G.; Orioli, M.; Maffei Facino, R. Antioxidant and radical scavenging activity of honey in endothelial cell cultures (EA.hy926). Planta Med. 2007, 73, 1182-1189. [CrossRef] [PubMed]

17. Deng, J.; Liu, R.; Lu, Q.; Hao, P.; Xu, A.; Zhang, J.; Tan, J. Biochemical properties, antibacterial and cellular antioxidant activities of buckwheat honey in comparison to manuka honey. Food Chem. 2018, 252, 243-249. [CrossRef]

18. Hazirah, H.; Yasmin Anum, M.Y.; Norwahidah, A.K. Antioxidant properties of stingless bee honey and its effect on the viability of lymphoblastoid cell line. Med. Health 2019, 14, 91-105.

19. Shen, S.; Wang, J.; Chen, X.; Liu, T.; Zhuo, Q.; Zhang, S.Q. Evaluation of cellular antioxidant components of honeys using UPLC-MS/MS and HPLC-FLD based on the quantitative composition-activity relationship. Food Chem. 2019, 293, 169-177. [CrossRef]

20. Giampieri, F.; Quiles, J.L.; Orantes-Bermejo, F.J.; Gasparrini, M.; Forbes-Hernandez, T.Y.; Sánchez-González, C.; Llopis, J.; Rivas-García, L.; Afrin, S.; Varela-López, A.; et al. Are by-products from beeswax recycling process a new promising source of bioactive compounds with biomedical properties? Food Chem. Toxicol. 2018, 112, 126-133. [CrossRef]

21. Markiewicz-Żukowska, R.; Naliwajko, S.K.; Bartosiuk, E.; Moskwa, J.; Isidorov, V.; Soroczyńska, J.; Borawska, M.H. Chemical composition and antioxidant activity of beebread, and its influence on the glioblastoma cell line (U87MG). J. Apic. Sci. 2013, 57, 147-157. [CrossRef]

22. Nakajima, Y.; Tsuruma, K.; Shimazawa, M.; Mishima, S.; Hara, H. Comparison of bee products based on assays of antioxidant capacities. BMC Complement. Altern. Med. 2009, 26, 1-9. [CrossRef] 
23. Karapetsas, A.; Voulgaridou, G.P.; Konialis, M.; Tsochantaridis, I.; Kynigopoulos, S.; Lambropoulou, M.; Stavropoulou, M.I.; Stathopoulou, K.; Aligiannis, N.; Bozidis, P.; et al. Propolis extracts inhibit UV-induced photodamage in human experimental in vitro skin models. Antioxidants 2019, 8, 125. [CrossRef] [PubMed]

24. Khacha-ananda, S.; Tragoolpua, K.; Chantawannakul, P.; Tragoolpua, Y. Antioxidant and anti-cancer cell proliferation activity of propolis extracts from two extraction methods. Asian Pac. J. Cancer Prev. 2013, 14, 6991-6995. [CrossRef] [PubMed]

25. Misir, S.; Aliyazicioglu, Y.; Demir, S.; Turan, I.; Yaman, S.O.; Deger, O. Antioxidant properties and protective effect of Turkish propolis on t-BHP-induced oxidative stress in foreskin fibroblast cells. Indian J. Pharm. Educ. 2018, 52, 94-100. [CrossRef]

26. Reis, J.H.O.; Barreto, G.A.; Cerqueira, J.C.; Anjos, J.P.D.; Andrade, L.N.; Padilha, F.F.; Druzian, J.I.; Machado, B.A.S. Evaluation of the antioxidant profile and cytotoxic activity of red propolis extracts from different regions of northeastern Brazil obtained by conventional and ultrasound-assisted extraction. PLOS ONE 2019, 14, e0219063. [CrossRef]

27. Touzani, S.; Embaslat, W.; Imtara, H.; Kmail, A.; Kadan, S.; Zaid, H.; ElArabi, I.; Badiaa, L.; Saad, B. In vitro evaluation of the potential use of propolis as a multitarget therapeutic product: Physicochemical properties, chemical composition, and immunomodulatory, antibacterial, and anticancer properties. Biomed. Res. Int. 2019, 4836378. [CrossRef]

28. Park, M.J.; Kim, B.Y.; Park, H.G.; Deng, Y.; Yoon, H.J.; Choi, Y.S.; Lee, K.S.; Jin, B.R. Major royal jelly protein 2 acts as an antimicrobial agent and antioxidant in royal jelly. J. Asia. Pac. Entomol. 2019, 22, 684-689. [CrossRef]

29. Park, M.J.; Kim, B.Y.; Deng, Y.; Park, H.G.; Choi, Y.S.; Lee, K.S.; Jin, B.R. Antioxidant capacity of major royal jelly proteins of honeybee (Apis mellifera) royal jelly. J. Asia. Pac. Entomol. 2020, 23, 445-448. [CrossRef]

30. Jin, T.Y.; Saravanakumar, K.; Wang, M.H. In vitro and in vivo antioxidant properties of water and methanol extracts of linden bee pollen. Biocatal. Agric. Biotechnol. 2018, 13, 186-189. [CrossRef]

31. Živković, L.; Bajić, V.; Dekanski, D.; Čabarkapa-Pirković, A.; Giampieri, F.; Gasparrini, M.; Mazzoni, L.; Potparević, B.S. Manuka honey attenuates oxidative damage induced by $\mathrm{H}_{2} \mathrm{O}_{2}$ in human whole blood in vitro. Food Chem. Toxicol. 2018, 119, 61-65. [CrossRef]

32. Campos, J.F.; dos Santos, U.P.; Macorini, L.F.; de Melo, A.M.; Balestieri, J.B.; Paredes-Gamero, E.J.; Cardoso, C.A.; de Picoli Souza, K.; dos Santos, E.L. Antimicrobial, antioxidant and cytotoxic activities of propolis from Melipona orbignyi (Hymenoptera, Apidae). Food Chem. Toxicol. 2014, 65, 374-380. [CrossRef]

33. Tamfu, A.N.; Sawalda, M.; Fotsing, M.T.; Kouipou, R.M.T.; Talla, E.; Chi, G.F.; Epanda, J.J.E.; Mbafor, J.T.; Baig, T.A.; Jabeen, A.; et al. A new isoflavonol and other constituents from Cameroonian propolis and evaluation of their anti-inflammatory, antifungal and antioxidant potential. Saudi J. Biol. Sci. 2020, 6, 1659-1666. [CrossRef] [PubMed]

34. Wozniak, M.; Mrówczynska, L.; Waskiewicz, A.; Rogozinski, T.; Ratajczak, I. The role of seasonality on the chemical composition, antioxidant activity and cytotoxicity of Polish propolis in human erythrocytes. Rev. Bras. Farmacogn. 2019, 29, 301-308. [CrossRef]

35. Cornara, L.; Biagi, M.; Xiao, J.; Burlando, B. Therapeutic properties of bioactive compounds from different honeybee products. Front. Pharmaco. 2017, 8, 412. [CrossRef] [PubMed]

36. Can, Z.; Yildiz, O.; Sahin, H.; Akyuz Turumtay, E.; Silici, S.; Kolayli, S. An investigation of Turkish honeys: Their physico-chemical properties, antioxidant capacities and phenolic profiles. Food Chem. 2015, 180, 133-141. [CrossRef]

37. Ares, A.M.; Valverde, S.; Bernal, J.L.; Nozal, M.J.; Bernal, J. Extraction and determination of bioactive compounds from bee pollen. J. Pharm. Biomed. Anal. 2018, 147, 110-124. [CrossRef] [PubMed]

38. da Silva, P.M.; Gauche, C.; Gonzaga, L.V.; Costa, A.C.; Fett, R. Honey: Chemical composition, stability and authenticity. Food Chem. 2016, 196, 309-323. [CrossRef] [PubMed]

39. Perna, A.; Simonetti, A.; Intaglietta, I.; Sofo, A.; Gambacorta, E. Metal content of southern Italy honey of different botanical origins and its correlation with polyphenol content and antioxidant activity. Int. J. Food Sci. Technol. 2012, 1909-1917. [CrossRef]

40. Li, Q.Q.; Wang, K.; Marcucci, M.C.; Sawaya, A.C.H.F.; Hu, L.; Xue, X.F.; Wu, L.M.; Hu, F.L. Nutrient-rich bee pollen: A treasure trove of active natural metabolites. J. Func. Food 2018, 49, 472-484. [CrossRef]

41. Chew, C.Y.; Chua, L.S.; Soontorngun, N.; Lee, C.T. Discovering potential bioactive compounds from Tualang honey. Agric. Nat. Resour. 2018, 52, 361-365. [CrossRef]

42. Bibi Sadeer, N.; Montesano, D.; Albrizio, S.; Zengin, G.; Mahomoodally, M.F. The versatility of antioxidant assays in food science and safety-chemistry, applications, strengths, and limitations. Antioxidants 2020, 9, 709. [CrossRef]

43. Combarros-Fuertes, P.; Estevinho, L.M.; Dias, L.G.; Castro, J.M.; Tomás-Barberán, F.A.; Tornadijo, M.E.; Fresno-Baro, J.M. Bioactive components and antioxidant and antibacterial activities of different varieties of honey: A screening prior to clinical application. J. Agric. Food Chem. 2019, 67, 688-698. [CrossRef]

44. Singleton, V.L.; Rossi, J.A. Colorimetry of total phenolics with phosphomolybdic-phosphotungstic acid reagents. Am. J. Enol. Vitic. 1965, 16, 144-158.

45. Chang, C.C.; Yang, M.H.; Wen, H.M.; Chern, J.C. Estimation of total flavonoid content in propolis by two complementary colorimetric methods. J. Food Drug Anal. 2002, 10, 178-182.

46. Arvouet-Grand, A.; Vennat, B.; Pourrat, A.; Legret, P. Standardisation d'un extrait de propolis et identification des principaux constituants [Standardization of propolis extract and identification of principal constituents]. J. Pharm. Belg. 1994, 49, 462-468. [PubMed]

47. Bankova, V.; Bertelli, D.; Borba, R.; Conti, B.J.; da Silva Cunha, I.B.; Danert, C.; Eberlin, M.N.; Falcão, S.I.; Isla, M.I.; Moreno, M.I.N.; et al. Standard methods for Apis mellifera propolis research. J. Apic. Res. 2019, 58, 1-49. [CrossRef] 
48. Dżugan, M.; Tomczyk, M.; Sowa, P.; Grabek-Lejko, D. Antioxidant activity as biomarker of honey variety. Molecules 2018, 23, 2069. [CrossRef]

49. Zarei, M.; Fazlara, A.; Tulabifard, N. Effect of thermal treatment on physicochemical and antioxidant properties of honey. Heliyon 2019, 5, e01894. [CrossRef]

50. Mot, A.C.; Silaghi-Dumitrescu, R.; Sârbu, C. Rapid and effective evaluation of the antioxidant capacity of propolis extracts using DPPH bleaching kinetic profiles, FT-IR and UV-vis spectroscopic data. J. Food Comp. Anal. 2011, 24, 516-522. [CrossRef]

51. Brand-Williams, W.; Cuvelier, M.E.; Berset, C. Use of a free radical method to evaluate antioxidant activity. LWT Food Sci. Technol. 1995, 28, 25-30. [CrossRef]

52. Benzie, I.F.; Strain, J.J. The ferric reducing ability of plasma (FRAP) as a measure of "antioxidant power": The FRAP assay. Anal. Biochem. 1996, 239, 70-76. [CrossRef] [PubMed]

53. Gülçin, I.; Bursal, E.; Sehitoğlu, M.H.; Bilsel, M.; Gören, A.C. Polyphenol contents and antioxidant activity of lyophilized aqueous extract of propolis from Erzurum, Turkey. Food Chem. Toxicol. 2010, 48, 2227-2238. [CrossRef] [PubMed]

54. Apak, R.; Kubilay, G.; Mustafa, O.; Karademir, E. Novel total antioxidant capacity index for dietary polyphenols and vitamins C and $\mathrm{E}$, using their cupric ion reducing capability in the presence of neocuproine: CUPRAC Method. J. Agric. Food Chem. 2004, 52, 7970-7981. [CrossRef] [PubMed]

55. Mouhoubi-Tafinine, Z.; Ouchemoukh, S.; Tamendjari, A. Antioxydant activity of some Algerian honey and propolis. Ind. Crops Prod. 2016, 88, 85-90. [CrossRef]

56. Oyaizu, M. Studies on products of browning reactions: Antioxidant activities of products of browning reaction prepared from glucosamine. J. Nutrit. 1986, 44, 307-315.

57. Prieto, P.; Pineda, M.; Aguilar, M. Spectrophotometric quantitation of antioxidant capacity through the formation of a phosphomolybdenum complex: Specific application to the determination of vitamin E. Anal. Biochem. 1999, 269, 337-341. [CrossRef]

58. Zhou, J.; Li, P.; Cheng, N.; Gao, H.; Wang, B.; Wei, Y.; Cao, W. Protective effects of buckwheat honey on DNA damage induced by hydroxyl radicals. Food Chem. Toxicol. 2012, 50, 2766-2773. [CrossRef]

59. Dinis, T.C.; Maderia, V.M.; Almeida, L.M. Action of phenolic derivatives (acetaminophen, salicylate, and 5-aminosalicylate) as inhibitors of membrane lipid peroxidation and as peroxyl radical scavengers. Arch. Biochem. Biophys. 1994, 315, 161-169. [CrossRef]

60. Ávila, S.; Hornung, P.S.; Teixeira, G.L.; Malunga, L.N.; Apea-Bah, F.B.; Beux, M.R.; Beta, T.; Ribani, R.H. Bioactive compounds and biological properties of Brazilian stingless bee honey have a strong relationship with the pollen floral origin. Food Res. Int. 2019, 123, 1-10. [CrossRef]

61. Ou, B.; Hampsch-Woodill, M.; Prior, R.L. Development and validation of an improved oxygen radical absorbance capacity assay using fluorescein as the fluorescent probe. J. Agric. Food Chem. 2001, 49, 4619-4626. [CrossRef]

62. Re, R.; Pellegrini, N.; Proteggente, A.; Pannala, A.; Yang, M.; Rice- Evans, C. Antioxidant activity applying an improved ABTS radical cation decolorization assay. Free Radic. Biol. Med. 1999, 26, 1231-1237. [CrossRef]

63. Alam, M.N.; Bristi, N.J.; Rafiquzzaman, M. Review on in vivo and in vitro methods evaluation of antioxidant activity. Saudi Pharm. J. 2013, 21, 143-152. [CrossRef] [PubMed]

64. Robak, J.; Gryglewski, R.J. Flavonoids are scavengers of superoxide anions. Biochem. Pharmacol. 1988, 37, 837-841. [CrossRef]

65. Kunchandy, E.; Rao, M.N.A. Oxygen radical scavenging activity of curcumin. Int. J. Pharm. 1990, 58, 237-240. [CrossRef]

66. Ruch, R.J.; Cheng, S.J.; Klaunig, J.E. Prevention of cytotoxicity and inhibition of intercellular communication by antioxidant catechins isolated from Chinese green tea. Carcinogen 1989, 10, 1003-1008. [CrossRef] [PubMed]

67. Gülçin, I. Antioxidants and antioxidant methods: An updated overview. Arch. Toxicol. 2020, 94, 651-715. [CrossRef] [PubMed]

68. Velioglu, Y.S.; Mazza, G.; Gao, L.; Oomah, B.D. Antioxidant activity and total phenolics in selected fruits, vegetables, and grain products. J. Agric. Food Chem. 1998, 46, 4113-4117. [CrossRef]

69. Prior, R.L.; Wu, X.L.; Schaich, K. Standardized methods for the determination of antioxidant capacity and phenolics in foods and dietary supplements. J. Agric. Food Chem. 2005, 53, 4290-4302. [CrossRef]

70. Council Directive 2001/110/EC of 20 December 2001 Relating to Honey. OJ L 10, 12.1. 2002, pp. 47-52. Available online: https: / / eur-lex.europa.eu/legal-content/EN/TXT/PDF/?uri=CELEX:02001L0110--20140623\&from=EN (accessed on 10 October 2020).

71. Crane, E. The World History of Beekeeping and Honey Hunting; Duckworth: London, UK, 1999; 682p.

72. Mračević, S.Đ.; Krstić, M.; Lolić, A.; Ražić, S. Comparative study of the chemical composition and biological potential of honey from different regions of Serbia. Microchem. J. 2020, 152, 104420. [CrossRef]

73. Alves, A.; Ramos, A.; Gonçalves, M.M.; Bernardo, M.; Mendes, B. Antioxidant activity, quality parameters and mineral content of Portuguese monofloral honeys. J. Food Comp. Anal. 2013, 30, 130-138. [CrossRef]

74. Attanzio, A.; Tesoriere, L.; Allegra, M.; Livrea, M.A. Monofloral honeys by Sicilian black honeybee (Apis mellifera ssp. sicula) have high reducing power and antioxidant capacity. Heliyon 2016, 2, e00193. [CrossRef]

75. Pauliuc, D.; Dranca, F.; Oroian, M. Antioxidant activity, total phenolic content, individual phenolics and physicochemical parameters suitability for Romanian honey authentication. Foods 2020, 9, 306. [CrossRef] [PubMed]

76. Rao, P.V.; Krishnan, K.T.; Salleh, N.; Gan, S.H. Biological and therapeutic effects of honey produced by honey bees and stingless bees: A comparative review. Rev. Bras. Farmacogn. 2016, 26, 657-664. [CrossRef]

77. Halagarda, M.; Groth, S.; Popek, S.; Rohn, S.; Pedan, V. Antioxidant activity and phenolic profile of selected organic and conventional honeys from Poland. Antioxidants (Basel) 2020, 9, 44. [CrossRef] [PubMed] 
78. Al-Farsi, M.; Al-Amri, A.; Al-Hadhrami, A.; Al-Belushi, S. Color, flavonoids, phenolics and antioxidants of Omani honey. Heliyon 2018, 4, e00874. [CrossRef] [PubMed]

79. Alotibi, I.A.; Harakeh, S.M.; Al-Mamary, M.; Mariod, A.A.; Al-Jaouni, S.K.; Al-Masaud, S.; Alharbi, M.G.; Al-Hindi, R.R. Floral markers and biological activity of Saudi honey. Saudi J. Biol. Sci. 2018, 25, 1369-1374. [CrossRef]

80. Alvarez-Suarez, J.M.; Tulipani, S.; Díaz, D.; Estevez, Y.; Romandini, S.; Giampieri, F.; Damiani, E.; Astolfi, P.; Bompadre, S.; Battino, M. Antioxidant and antimicrobial capacity of several monofloral Cuban honeys and their correlation with color, polyphenol content and other chemical compounds. Food Chem. Toxicol. 2010, 48, 2490-2499. [CrossRef]

81. Alvarez-Suarez, J.M.; Giampieri, F.; Brenciani, A.; Mazzoni, L.; Gasparrini, M.; González-Paramás, A.M.; Santos-Buelga, C.; Morroni, G.; Forbes-Hernández, T.Y.; Simoni, S.; et al. Apis mellifera vs melipona beecheii Cuban polifloral honeys: A comparison based on their physicochemical parameters, chemical composition and biological properties. LWT Food Sci. Technol. 2018, 87, 272-279. [CrossRef]

82. Biluca, F.C.; da Silva, B.; Caon, T.; Mohr, E.T.B.; Vieira, G.N.; Gonzaga, L.V.; Vitali, L.; Micke, G.; Fett, R.; Dalmarco, E.M.; et al. Investigation of phenolic compounds, antioxidant and anti-inflammatory activities in stingless bee honey (Meliponinae). Food Res. Int. 2020, 129, 108756. [CrossRef]

83. Biluca, F.C.; Braghini, F.; Gonzaga, L.V.; Costa, A.C.O.; Fett, R. Physicochemical profiles, minerals and bioactive compounds of stingless bee honey (Meliponinae). J. Food Comp. Anal. 2016, 50, 61-69. [CrossRef]

84. Bodó, A.; Radványi, L.; Kőszegi, T.; Csepregi, R.; Nagy, D.U.; Farkas, Á.; Kocsis, M. Melissopalynology, antioxidant activity and multielement analysis of two types of early spring honeys from Hungary. Food Bios. 2020, 35, 100587. [CrossRef]

85. Serra Bonvehi, J.; Ventura Coll, F.; Orantes Bermejo, J.F. Characterization of avocado honey (Persea americana Mill.) produced in Southern Spain. Food Chem. 2019, 287, 214-221. [CrossRef] [PubMed]

86. Chang, X.; Wang, J.; Yang, S.; Chen, S.; Song, Y. Antioxidative, antibrowning and antibacterial activities of sixteen floral honeys. Food Funct. 2011, 2, 541-546. [CrossRef] [PubMed]

87. da Silva, I.A.; da Silva, T.M.; Camara, C.A.; Queiroz, N.; Magnani, M.; de Novais, J.S.; Soledade, L.E.; Lima, E.O.; de Souza, A.L.; de Souza, A.G. Phenolic profile, antioxidant activity and palynological analysis of stingless bee honey from Amazonas, Northern Brazil. Food Chem. 2013, 141, 3552-3558. [CrossRef] [PubMed]

88. Bolanos de la Torre, A.A.; Henderson, T.; Nigam, P.S.; Owusu-Apenten, R.K. A universally calibrated microplate ferric reducing antioxidant power (FRAP) assay for foods and applications to Manuka honey. Food Chem. 2015, 174, 119-123. [CrossRef]

89. Duarte, A.W.F.; Vasconcelos, M.R.; Melissa Oda-Souza, M.; de Oliveira, F.F.; Lòpez, A.M.Q. Honey and bee pollen produced by Meliponini (Apidae) in Alagoas, Brazil: Multivariate analysis of physicochemical and antioxidant profiles. Food Sci. Technol. 2018, 38, 493-503. [CrossRef]

90. Dżugan, M.; Grabek-Lejko, D.; Swacha, S.; Tomczyk, M.; Bednarska, S.; Kapusta, I. Physicochemical quality parameters, antibacterial properties and cellular antioxidant activity of Polish buckwheat honey. Food Biosci. 2020, 34, 100538. [CrossRef]

91. El-Haskoury, R.; Kriaa, W.; Lyoussi, B.; Makni, M. Ceratonia siliqua honeys from Morocco: Physicochemical properties, mineral contents, and antioxidant activities. J. Food Drug Anal. 2018, 26, 67-73. [CrossRef]

92. Escuredo, O.; Míguez, M.; Fernández-González, M.; Carmen Seijo, M. Nutritional value and antioxidant activity of honeys produced in a European Atlantic area. Food Chem. 2013, 138, 851-856. [CrossRef]

93. Shantal Rodríguez Flores, M.; Escuredo, O.; Carmen Seijo, M. Assessment of physicochemical and antioxidant characteristics of Quercus pyrenaica honeydew honeys. Food Chem. 2015, 166, 101-106. [CrossRef]

94. Gorjanović, S.; Alvarez-Suarez, J.M.; Novaković, M.M.; Pastor, F.T.; Pezo, L.; Battino, M.; Sužnjevic, D.Ž. Comparative analysis of antioxidant activity of honey of different floral sources using recently developed polarographic and various spectrophotometric assays. J. Food Comp. Anal. 2013, 30, 13-18. [CrossRef]

95. Gül, A.; Pehlivan, T. Antioxidant activities of some monofloral honey types produced across Turkey. Saudi J. Biol. Sci. 2018, 25, 1056-1065. [CrossRef] [PubMed]

96. Karabagias, I.K.; Karabournioti, S.; Karabagias, V.K.; Badeka, A.V. Palynological, physico-chemical and bioactivity parameters determination, of a less common Greek honeydew honey: "dryomelo". Food Cont. 2020, 109, 106940. [CrossRef]

97. Kek, S.P.; Chin, N.L.; Yusofa, Y.A.; Tan, S.W.; Chua, L.S. Total phenolic contents and colour intensity of Malaysian honeys from the Apis spp. and Trigona spp. bees. Agric. Agric. Sci. Procedia 2014, 2, 150-155. [CrossRef]

98. Kishore, R.K.; Halim, A.S.; Syazana, M.S.; Sirajudeen, K.N. Tualang honey has higher phenolic content and greater radical scavenging activity compared with other honey sources. Nutr. Res. 2011, 31, 322-325. [CrossRef] [PubMed]

99. Kuś, P.M.; Congiu, F.; Teper, D.; Sroka, Z.; Jerković, I.; Tuberoso, C.I.G. Antioxidant activity, color characteristics, total phenol content and general HPLC fingerprints of six Polish unifloral honey types. LWT Food Sci. Technol. 2014, 55, 124-130. [CrossRef]

100. Lachman, J.; Orsák, M.; Hejtmánková, A.; Kovářova, E. Evaluation of antioxidant activity and total phenolics of selected Czech honeys. LWT Food Sci. Technol. 2010, 43, 52-58. [CrossRef]

101. Lianda, R.L.P.; D'Oliveira Sant'Ana, L.; EchevarriaI, A.; Castro, R.N. Antioxidant activity and phenolic composition of brazilian honeys and their extracts. J. Braz. Chem. Soc. 2012, 4, 618-627. [CrossRef]

102. Liu, J.R.; Ye, Y.L.; Lin, T.Y.; Wang, Y.W.; Peng, C.C. Effect of floral sources on the antioxidant, antimicrobial, and anti-inflammatory activities of honeys in Taiwan. Food Chem. 2013, 139, 938-943. [CrossRef]

103. Marshall, S.M.; Schneider, K.R.; Cisneros, K.V.; Gu, L. Determination of antioxidant capacities, $\alpha$-dicarbonyls, and phenolic

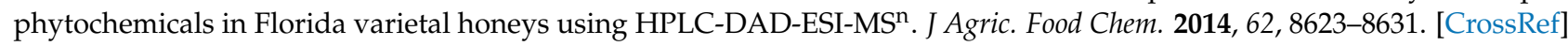


104. Nascimento, K.S.; Gasparotto Sattler, J.A.; Lauer Macedo, L.F.; Serna González, C.V.; Pereira de Melo, I.L.; da Silva Araújo, E.; Granato, D.; Sattler, A.; Bicudo de Almeida-Muradian, L. Phenolic compounds, antioxidant capacity and physicochemical properties of Brazilian Apis mellifera honeys. LWT Food Sci. Technol. 2018, 91, 85-94. [CrossRef]

105. Nayik, G.A.; Nanda, V. A chemometric approach to evaluate the phenolic compounds, antioxidant activity and mineral content of different unifloral honey types from Kashmir, India. LWT Food Sci. Technol. 2016, 74, 504-513. [CrossRef]

106. Nayik, G.A.; Suhag, Y.; Majid, I.; Nanda, V. Discrimination of high altitude Indian honey by chemometric approach according to their antioxidant properties and macro minerals. J. Saudi Soc. Agric. Sci. 2018, 17, 200-207. [CrossRef]

107. Ozcan, M.M.; Olmez, C. Some qualitative properties of different monofloral honeys. Food Chem. 2014, 163, 212-218. [CrossRef] [PubMed]

108. Rodríguez, B.A.; Mendoza, S.; Iturriga, M.H.; Castaño-Tostado, E. Quality parameters and antioxidant and antibacterial properties of some Mexican honeys. J Food Sci. 2012, 77, C121-C127. [CrossRef] [PubMed]

109. Rodríguez-Flores, M.S.; Escuredo, O.; Míguez, M.; Seijo, M.C. Differentiation of oak honeydew and chestnut honeys from the same geographical origin using chemometric methods. Food Chem. 2019, 297, 124979. [CrossRef]

110. Shafiee, S.; Minaei, S.; Moghaddam-Charkari, N.; Barzegar, M. Honey characterization using computer vision system and artificial neural networks. Food Chem. 2014, 159, 143-150. [CrossRef]

111. Silici, S.; Sagdic, O.; Ekici, L. Total phenolic content, antiradical, antioxidant and antimicrobial activities of Rhododendron honeys. Food Chem. 2010, 121, 238-243. [CrossRef]

112. Silva, T.M.S.; dos Santos, F.P.; Evangelista-Rodrigues, A.; da Silva, E.M.S.; da Silva, G.S.; de Novais, J.S.; dos Santos, F.A.R.; Camara, C.A. Phenolic compounds, melissopalynological, physicochemical analysis and antioxidant activity of jandaíra (Melipona subnitida) honey. J. Food Comp. Anal. 2013, 29, 10-18. [CrossRef]

113. Silva, I.P.; Caldas, M.J.M.; Machado, C.S.; do Nascimento, A.S.; Lordêlo, M.S.; Bárbara, M.F.S.; Evangelista-Barreto, N.S.; Estevinho, L.M.; de Carvalho, C.A.L. Antioxidants activity and physicochemical properties of honey from social bees of the Brazilian semiarid region. J. Apic. Res. 2020, 1823671. [CrossRef]

114. Sousa, J.M.; de Souza, E.L.; Marques, G.; Meireles, B.; de Magalhães Cordeiro, Â.T.; Gullón, B.; Pintado, M.M.; Magnani, M. Polyphenolic profile and antioxidant and antibacterial activities of monofloral honeys produced by Meliponini in the Brazilian semiarid region. Food Res. Int. 2016, 84, 61-68. [CrossRef]

115. Tornuk, F.; Karaman, S.; Ozturk, I.; Toker, O.S.; Tastemur, B.; Sagdic, O.; Dogan, M.; Kayacier, A. Quality characterization of artisanal and retail Turkish blossom honeys: Determination of physicochemical, microbiological, bioactive properties and aroma profile. Ind. Crop. Prod. 2013, 46, 124-131. [CrossRef]

116. Vasić, V.; Gašić, U.; Stanković, D.; Lušić, D.; Vukić-Lušić, D.; Milojković-Opsenica, D.; Tešić, Ž.; Trifković, J. Towards better quality criteria of European honeydew honey: Phenolic profile and antioxidant capacity. Food Chem. 2019, 274, 629-641. [CrossRef] [PubMed]

117. Wilczyńska, A. Effect of filtration on colour, antioxidant activity and total phenolics of honey. LWT Food Sci. Technol. 2014, 57, 767-774. [CrossRef]

118. Pascoal, A.; Rodrigues, S.; Teixeira, A.; Feás, X.; Estevinho, L.M. Biological activities of commercial bee pollens: Antimicrobial, antimutagenic, antioxidant and anti-inflammatory. Food Chem. Toxicol. 2014, 63, 233-239. [CrossRef] [PubMed]

119. De-Melo, A.A.M.; Estevinho, M.L.M.F.; Gasparotto Sattler, J.A.; Souza, B.R.; da Silva Freitas, A.; Barth, O.M.; Almeida-Muradian, L.B. Effect of processing conditions on characteristics of dehydrated bee-pollen and correlation between quality parameters. $L W T$ Food Sci. Technol. 2016, 65, 808-815. [CrossRef]

120. Denisow, B.; Denisow-Pietrzyk, M. Biological and therapeutic properties of bee pollen: A review. J. Sci. Food Agric. 2016, 96, 4303-4309. [CrossRef]

121. Zuluaga, C.M.; Serrato, J.C.; Quicazan, M.C. Chemical, nutritional and bioactive characterization of Colombian bee-bread. Chem. Eng. Trans. 2015, 43, 175-180.

122. Estevinho, L.M.; Dias, T.; Anjos, O. Influence of the storage conditions (frozen vs. dried) in health-related lipid indexes and antioxidants of bee pollen. Eur. J. Lipid Sci. Technol 2018, 1800393.

123. De-Melo, A.A.M.; Estevinho, L.M.; Moreira, M.M.; Delerue-Matos, C.; da Silva de Freitas, A.; Barth, O.M.; de Almeida-Muradian, L.B. A multivariate approach based on physicochemical parameters and biological potential for the botanical and geographical discrimination of Brazilian bee pollen. Food Biosci. 2018, 25, 91-110. [CrossRef]

124. Bakour, M.; Fernandes, A.; Barros, L.; Sokovic, M.; Ferreira, I.C.F.R.; Iyoussi, B. Bee bread as a functional product: Chemical composition and bioactive properties. Food Sci. Technol. 2019, 109, 276-282. [CrossRef]

125. Kaškonienè, V.; Adaškevičiūte, V.; Kaškonas, P.; Mickiene, R.; Maruška, A. Antimicrobial and antioxidant activities of natural and fermented bee pollen. Food Biosci. 2020, 34, 100532. [CrossRef]

126. Bogdanov, S. Pollen: Production, nutrition and health: A review. Bee Prod. Sci. 2017, 36. Available online: http://www.beehexagon.net/ (accessed on 10 November 2020).

127. Atsalakis, E.; Chinou, I.; Makropoulou, M.; Karabournioti, S.; Graikou, K. Evaluation of phenolic compounds in Cistus creticus bee pollen from Greece. Antioxidant and antimicrobial properties. Nat. Prod. Comm. 2017, 12, 1813-1816. [CrossRef]

128. de Florio Almeida, J.; dos Reis, A.S.; Heldt, L.F.S.; Pereira, D.; Bianchin, M.; de Moura, C.; Plata-Oviedo, M.V.; Haminiuk, C.W.I.; Ribeiro, I.S.; da Luz, C.F.P.; et al. Lyophilized bee pollen extract: A natural antioxidant source to prevent lipid oxidation in refrigerated sausages. LWT Food Sci. Technol. 2017, 76, 299-305. [CrossRef] 
129. Fadzilah, N.H.J.; Mohd, F.; Jajuli, R.; Omar, W.A.W. Total phenolic content, total flavonoid and antioxidant activity of ethanolic bee pollen extracts from three species of Malaysian stingless bee. J. Apic. Res. 2017, 56, 130-135. [CrossRef]

130. Graikou, K.; Kapeta, S.; Aligiannis, N.; Sotiroudis, G.; Chondrogianni, N.; Gonos, E.; Chinou, I. Chemical analysis of Greek pollen-Antioxidant, antimicrobial and proteasome activation properties. Chem. Central J. 2011, 5, 33. [CrossRef] [PubMed]

131. Kalaycioglu, Z.; Kaygusuz, H.; Doker, S.; Kolayli, S.; Erim, F.B. Characterization of Turkish honeybee pollens by principal component analysis based on their individual organic acids, sugars, minerals, and antioxidant activities. LWT Food Sci. Technol. 2017, 84, 402-408. [CrossRef]

132. Su, J.; Yang, X.; Lu, Q.; Liu, R. Antioxidant and anti-tyrosinase activities of bee pollen and identification of active components. J. Apic. Res. 2020. [CrossRef]

133. Morais, M.; Moreira, L.; Feás, X.; Estevinho, L.M. Honeybee-collected pollen from five Portuguese Natural Parks: Palynological origin, phenolic content, antioxidant properties and antimicrobial activity. Food Chem. Toxicol. 2011, 49, 1096-1101. [CrossRef] [PubMed]

134. Ulusoy, E.; Kolayli, S. Phenolic composition and antioxidant properties of Anzer bee pollen. J. Food Biochem. 2014, 38, 73-82. [CrossRef]

135. Ivanišová, E.; Kačániová, M.; Frančáková, H.; Petrová, J.; Hutková, J.; Brovarskyi, V.; Velychko, S.; Adamchuk, L.; Schubertová, Z.; Musilová, J. Bee bread-Perspective source of bioactive compounds for future. Potravinarstvo Slovak J. Food Sci. 2015, 9, 592-598. [CrossRef]

136. Węglińska, M.; Szostak, R.; Kita, A.; Nemś, A.; Mazurek, S. Determination of nutritional parameters of bee pollen by Raman and infrared spectroscopy. Talanta 2020, 212, 120790. [CrossRef]

137. Borycka, K.; Grabek-Lejko, D.; Kasprzyk, I. Antioxidant and antibacterial properties of commercial bee pollen products. J. Apic. Res. 2015, 54, 491-502. [CrossRef]

138. Al-Waili, N.; Al-Ghamdi, A.; Ansari, M.J.; Al-Attal, Y.; Salom, K. Synergistic effects of honey and propolis toward drug multiresistant Staphylococcus aureus, Escherichia coli and Candida albicans isolates in single and polymicrobial cultures. Int. J. Med. Sci 2012, 9, 793-800. [CrossRef] [PubMed]

139. Sforcin, J.M. Biological properties and therapeutic applications of propolis. Phytother. Res. 2016, 6, 894-905. [CrossRef] [PubMed]

140. Graikou, K.; Popova, M.; Gortzi, O.; Bankova, V.; Chinou, I. Characterization and biological evaluation of selected Mediterranean propolis samples. Is it a new type? LWT Food Sci. Technol. 2016, 65, 261-267. [CrossRef]

141. Abdullah, N.A.; Ja'afar, F.; Yasin, H.M.; Taha, H.; Petalcorin, M.I.R.; Mamit, M.H.; Kusrini, E.; Usman, A. Physicochemical analyses, antioxidant, antibacterial, and toxicity of propolis particles produced by stingless bee Heterotrigona itama found in Brunei Darussalam. Heliyon 2019, 5, e02476. [CrossRef]

142. Bittencourt, M.L.F.; Ribeiro, P.R.; Franco, R.L.P.; Hilhorst, H.W.M.; de Castro, R.D.; Fernandez, L.G. Metabolite profiling, antioxidant and antibacterial activities of Brazilian propolis: Use of correlation and multivariate analyses to identify potential bioactive compounds. Food Res. Int. 2015, 76, 449-457. [CrossRef]

143. Castro, C.; Mura, F.; Valenzuela, G.; Figueroa, C.; Salinas, R.; Zuñiga, M.C.; Torres, J.L.; Fuguet, E.; Delporte, C. Identification of phenolic compounds by HPLC-ESI-MS/MS and antioxidant activity from Chilean propolis. Food Res. Int. 2014, 64, 873-879. [CrossRef]

144. Cavalaro, R.I.; Cruz, R.G.D.; Dupont, S.; de Moura Bell, J.M.L.N.; Vieira, T.M.F.S. In vitro and in vivo antioxidant properties of bioactive compounds from green propolis obtained by ultrasound-assisted extraction. Food Chem. X 2019, 4, 100054. [CrossRef]

145. Calegari, M.A.; Ayres, B.B.; dos Santos Tonial, L.M.; de Alencar, S.M.; Oldoni, T.L.C. Fourier transform near infrared spectroscopy as a tool for predicting antioxidant activity of propolis. J. King Saud Univ. Sci. 2020, 32, 784-790. [CrossRef]

146. Silva, C.C.F.D.; Salatino, A.; Motta, L.B.D.; Negri, G.; Salatino, M.L.F. Chemical characterization, antioxidant and anti-HIV activities of a Brazilian propolis from Ceará state. Braz. J. Pharmacogn. 2019, 29, 309-318. [CrossRef]

147. Escriche, I.; Juan-Borrás, M. Standardizing the analysis of phenolic profile in propolis. Food Res. Int. 2018, 106, 834-841. [CrossRef]

148. Ferreira, B.L.; Gonzaga, L.V.; Vitali, L.; Micke, G.A.; Maltez, H.F.; Ressureição, C.; Costa, A.C.O.; Fett, R. Southern-Brazilian geopropolis: A potential source of polyphenolic compounds and assessment of mineral composition. Food Res. Int. 2019, 126, 108683. [CrossRef]

149. Freitas, A.S.; Cunha, A.; Cardoso, S.M.; Oliveira, R.; Almeida-Aguiar, C. Constancy of the bioactivities of propolis samples collected on the same apiary over four years. Food Res. Int. 2019, 119, 622-633. [CrossRef]

150. Laskar, R.A.; Sk, I.; Roy, N.; Begum, N.A. Antioxidant activity of Indian propolis and its chemical constituents. Food Chem. 2010, 122, 233-237. [CrossRef]

151. Miguel, M.G.; Nunes, S.; Dandlen, S.A.; Cavaco, A.M.; Antunes, M.D. Phenols and antioxidant activity of hydro-alcoholic extracts of propolis from Algarve, South of Portugal. Food Chem. Toxicol. 2010, 48, 3418-3423. [CrossRef]

152. Ozdal, T.; Ceylan, F.D.; Eroglu, N.; Kaplan, M.; Olgun, E.O.; Capanoglu, E. Investigation of antioxidant capacity, bioaccessibility and LC-MS/MS phenolic profile of Turkish propolis. Food Res. Int. 2019, 122, 528-536. [CrossRef]

153. Potkonjak, N.I.; Veselinović, D.S.; Novaković, M.M.; Gorjanović, S.Ž.; Pezo, L.L.; Sužnjević, D.Ž. Antioxidant activity of propolis extracts from Serbia: A polarographic approach. Food Chem. Toxicol. 2012, 50, 3614-3618. [CrossRef]

154. Ristivojevic, P.; Dimkic, I.; Guzelmeric, E.; Trifkovic, J.; Knezevic, M.; Beric, T.; Yesilada, E.; Milojković-Opsenica, D.; Stankovic, S. Profiling of Turkish propolis subtypes: Comparative evaluation of their phytochemical compositions, antioxidant and antimicrobial activities. LWT Food Sci. Technol. 2018, 95, 367-379. [CrossRef] 
155. Sadhana, N.; Lohidasan, S.; Mahadik, K.R. Marker-based standardization and investigation of nutraceutical potential of Indian propolis. J. Integr. Med. 2017, 15, 483-494. [CrossRef]

156. Silva, J.C.; Rodrigues, S.; Feás, X.; Estevinho, L.M. Antimicrobial activity, phenolic profile and role in the inflammation of propolis. Food Chem. Toxicol. 2012, 50, 1790-1795. [CrossRef]

157. Sulaiman, G.M.; Al Sammarrae, K.W.; Ad'hiah, A.H.; Zucchetti, M.; Frapolli, R.; Bello, E.; Erba, E.; D’Incalci, M.; Bagnati, R. Chemical characterization of Iraqi propolis samples and assessing their antioxidant potentials. Food Chem. Toxicol. 2011, 49, 2415-2421. [CrossRef] [PubMed]

158. Yusop, S.A.T.W.; Sukairi, A.H.; Sabri, W.M.A.W.; Asaruddin, M.R. Antioxidant, antimicrobial and cytotoxicity activities of propolis from Beladin, Sarawak stingless bees Trigona itama extract. Mater. Today Proceed. 2019, 19, 1752-1760. [CrossRef]

159. Svečnjak, L.; Chesson, L.A.; Gallina, A.; Maia, M.; Martinello, M.; Mutinelli, F.; Muz, M.N.; Nunes, F.M.; Saucy, F.; Tipple, B.J.; et al. Standard methods for Apis mellifera beeswax research. J. Apic. Res. 2019, 58, 1-108. [CrossRef]

160. Münstedt, K.; Bogdanov, S. Bee products and their potential use in modern medicine. J. ApiProd. ApiMed. Sci. 2009, 1, 57-63. [CrossRef]

161. Zhao, H.; Zhu, M.; Wang, K.; Yang, E.; Su, J.; Wang, Q.; Cheng, N.; Xue, X.; Wu, L.; Cao, W. Identification and quantitation of bioactive components from honeycomb (Nidus Vespae). Food Chem. 2020, 314, 126052. [CrossRef]

162. Giampieri, F.; Gasparrini, M.; Forbes-Hernández, T.Y.; Manna, P.P.; Zhang, J.; Reboredo-Rodríguez, P.; Cianciosi, D.; Quiles, J.L.; Torres Fernández-Piñar, C.; Orantes-Bermejo, F.J.; et al. Beeswax by-products efficiently counteract the oxidative damage induced by an oxidant agent in human dermal fibroblasts. Int. J. Mol. Sci. 2018, 19, 2842. [CrossRef]

163. Pavel, C.I.; Mărghitaş, L.A.; Dezmirean, D.S.; Tomoş, L.I.; Bonta, V.; Şapcaliu, A.; Buttstedt, A. Comparison between local and commercial royal jelly-Use of antioxidant activity and 10-hydroxy-2-decenoic acid as quality parameter. J. Apic. Res. 2014, 53, 116-123. [CrossRef]

164. Frangieh, J.; Salma, Y.; Haddad, K.; Mattei, C.; Legros, C.; Fajloun, Z.; El Obeid, D. First characterization of the venom from Apis mellifera syriaca, a honeybee from the Middle East region. Toxins 2019, 11, 191. [CrossRef]

165. Sobral, F.; Sampaio, A.; Falcão, S.; Queiroz, M.J.; Calhelha, R.C.; Vilas-Boas, M.; Ferreira, I.C. Chemical characterization, antioxidant, anti-inflammatory and cytotoxic properties of bee venom collected in Northeast Portugal. Food Chem. Toxicol. 2016, 94, 172-177. [CrossRef]

166. Somwongin, S.; Chantawannakul, P.; Chaiyana, W. Antioxidant activity and irritation property of venoms from Apis species. Toxicon 2018, 145, 32-39. [CrossRef]

167. Hu, F.; Bíliková, K.; Casabianca, H.; Daniele, G.; Espindola, F.S.; Feng, M.; Guan, C.; Han, B.; Kraková, T.K.; Li, J.; et al. Standard methods for Apis mellifera royal jelly research. J. Apic. Res. 2019, 58, 1-68. [CrossRef]

168. Ramanathan, A.N.K.G.; Nair, A.J.; Sugunan, V.S. A review on royal jelly proteins and peptides. J. Func. Foods 2018, 44, 255-264. [CrossRef]

169. Ramadan, M.; Al-Ghamdi, A. Bioactive compounds and health-promoting properties of royal jelly: A review. J. Func. Foods 2012, 4, 39-52. [CrossRef]

170. Kunugi, H.; Mohammed Ali, A. Royal jelly and its components promote healthy aging and longevity: From animal models to humans. Int. J. Mol. Sci. 2019, 20, 4662. [CrossRef] [PubMed]

171. Nagai, T.; Inoue, R. Preparation and functional properties of water extract and alkaline extract of royal jelly. Food Chem. 2004, 84, 181-186. [CrossRef]

172. Liu, J.R.; Yang, Y.C.; Shi, L.S.; Peng, C.C. Antioxidant properties of royal jelly associated with larval age and time of harvest. J. Agric. Food Chem. 2008, 56, 11447-11452. [CrossRef]

173. Sı̆̆g, A.K.; Öz-Sı̆̆g, Ö.; Güney, M. Royal jelly: A natural therapeutic? Ortadogu Tıp Derg 2019, 11, $333-341$.

174. Bogdanov, S. Bee venom: Composition, health, medicine: A Review. Bee Prod. Sci. 2017, 24. Available online: http://www.beehexagon.net/ (accessed on 11 November 2020).

175. El-Seedi, H.R.; Khalifa, S.A.M.; El-Wahed, A.A.; Gao, R.; Guo, Z.; Tahir, H.E.; Zhao, C.; Du, M.; Farag, M.A.; Musharraf, S.G.; et al. Honeybee products: An updated review of neurological actions. Trends Food Sci. Technol. 2020, 101, 17-27. [CrossRef]

176. Awad, K.; Abushouk, A.I.; AbdelKarim, A.H.; Mohammed, M.; Negida, A.; Shalash, A.S. Bee venom for the treatment of Parkinson's disease: How far is it possible? Biomed. Pharmacother. 2017, 91, 295-302. [CrossRef]

177. Premratanachai, P.; Chanchao, C. Review of the anticancer activities of bee products. Asian Pac. J. Trop. Biomed. 2014, 4, 337-344. [CrossRef]

178. Zhang, S.; Liu, Y.; Ye, Y.; Wang, X.R.; Lin, L.T.; Xiao, L.Y.; Zhou, P.; Shi, G.X.; Liu, C.Z. Bee venom therapy: Potential mechanisms and therapeutic applications. Toxicon 2018, 148, 64-73. [CrossRef] [PubMed]

179. Hanafi, M.Y.; Zaher, E.L.M.; El-Adely, S.E.M.; Sakr, A.; Ghobashi, A.H.M.; Hemly, M.H.; Kazem, A.H.; Kamel, M.A. The therapeutic effects of bee venom on some metabolic and antioxidant parameters associated with HFD-induced non-alcoholic fatty liver in rats. Exp. Ther Med. 2018, 15, 5091-5099. [CrossRef] [PubMed]

180. Gu, H.; Song, I.B.; Han, H.J.; Lee, N.Y.; Cha, J.Y.; Son, Y.K.; Kwon, J. Antioxidant activity of royal jelly hydrolysates obtained by enzymatic treatment. Korean J. Food Sci. Anim. Resour. 2018, 38, 135-142. [PubMed]

181. Mohdaly, A.A.A.; Mahmoud, A.A.; Roby, M.H.H.; Smetanska, I.; Ramadan, M.F. Phenolic extract from propolis and bee pollen: Composition, antioxidant and antibacterial activities. J. Food Biochem. 2015, 39, 538-547. [CrossRef] 